\title{
No conversion, no conversation: consequences of retail salespeople disengaging from unpromising prospects
}

\author{
William L. Cron ${ }^{1,2} \cdot$ Sascha Alavi ${ }^{2} \cdot$ Johannes Habel ${ }^{3,4} \cdot$ Jan Wieseke ${ }^{2,5} \cdot$ Hanaa Ryari $^{2}$
}

Received: 17 July 2019 / Accepted: 6 December 2020 / Published online: 13 January 2021

(C) The Author(s) 2021

\begin{abstract}
On encountering a prospect whom they believe unlikely to make a purchase, some retail salespeople adopt a sales strategy of limiting engagement with the customer, relying on a "no conversion, no conversation" ( $\left.\mathrm{NC}^{2}\right)$ sales strategy. Is this a good or bad sales strategy? Based on a multisource dataset combining salespeople and objective sales performance data, the authors examine retail salespeople's performance consequences of disengaging from a customer, i.e., of the $\mathrm{NC}^{2}$ sales strategy. Higher sales performance and sales growth arises from the use of an $\mathrm{NC}^{2}$ sales strategy when (1) salespeople are experienced professionals skilled in gauging customers' purchase likelihood, (2) store traffic is high, and (3) salespeople are oriented to building lasting customer relationships. However, (4) when store traffic is low and peers use the $\mathrm{NC}^{2}$ sales strategy as well, this customer disengagement strategy yields lower returns for salespeople.
\end{abstract}

Keywords Personal selling $\cdot$ Time allocation $\cdot$ Decision strategy $\cdot$ Intuition $\cdot$ Salesperson-customer relationships

Developing an appropriate sales strategy for customers not intending to make a purchase is becoming increasingly important in retailing. Retail salespeople have always faced a challenge in responding to a customer they feel does not intend to make a purchase while visiting a retail store. Channel multiplicity and emerging shopping habits, especially among millennials, has exacerbated this already challenging situation. Verhoef et al. (2007) refer to this shopping behavior as "research shopping," also referred to as "showrooming" in the popular press (Gensler et al. 2017; Koetsier 2018). Clearly, how a retail salesperson deals with customer showrooming and non-purchase intentions is an issue of growing

Lisa Scheer served as Area Editor for this article. importance. A recent study, for instance, found showrooming to be deleterious to retail salespeople both psychologically and in terms of their performance (Rapp et al. 2015).

Conversely, the advisability of disengaging from a customer, even one who does not intend to make a purchase at that time, is not clear. This is despite the fact that the practice of establishing and maintaining customer relationships is loudly trumpeted in popular business press (e.g., Narayandas 2005) and supported in academic literature as well (e.g., Reynolds and Beatty 1999; Dimple 2017). Disengaging from a customer, even one judged unlikely to make a purchase, seems to be at odds with the customer relationship mantra.
Sascha Alavi

sascha.alavi@rub.de

William L. Cron

b.cron@tcu.edu

Johannes Habel

jhabel@bauer.uh.edu

Jan Wieseke

jan.wieseke@rub.de

Hanaa Ryari

hanaa.ryari@rub.de
Fort Worth, USA

2 Sales Management Department, University of Bochum, Universitätsstraße 150, 44780 Bochum, Germany

3 C.T. Bauer College of Business, University of Houston, 4750 Calhoun Road, Houston, TX 77204-6021, USA

4 Warwick Business School, University of Warwick, Scarman Road, Coventry CV4 7AL, UK

5 Loughborough University, Loughborough, UK 
Salespeople face a demanding decision in sales encounters when sensing that a prospect is not likely to make a purchase. Should they invest more time attempting to convert the prospect, or should they end the sales conversation to save time? In this study, we focus on a specific salesperson sales strategy of whether to end a sales encounter with a prospect when a salesperson perceives that the customer is not likely to purchasethat is, the "no conversion, no conversation" sales strategy or, in short, the $\mathrm{NC}^{2}$ strategy.

The rationale for using the $\mathrm{NC}^{2}$ strategy is that it frees up time to consult with other, more promising prospects. Recent studies indicate that salespeople spend only $41 \%$ of their working time in interactions with customers (CSO Insights 2011); however, on average, only $17 \%$ of sales talks result in a closed deal (Graham 2013). In other words, more than four out of five prospect encounters do not immediately contribute to salespeople's sales performance. Thus, salespeople may be under pressure to use their time efficiently.

While the purpose of engaging in the $\mathrm{NC}^{2}$ sales strategy is to enhance overall sales performance, it is uncertain whether this strategy achieves this purpose. Engaging in the $\mathrm{NC}^{2}$ sales strategy may result in time savings, but it also may have an adverse effect on salespeople's performance, e.g., if their intuition is inaccurate (i.e., erroneously concluding that a customer is not likely to purchase) or if it undermines a potential relationship between the customer and the firm. The $\mathrm{NC}^{2}$ sales strategy, therefore, might be a double-edged sword. Thus, the question arises whether the $\mathrm{NC}^{2}$ sales strategy is ultimately beneficial or detrimental for salespeople.

We employ growth analysis to account for the possibility that the $\mathrm{NC}^{2}$ sales strategy influences a salesperson's level of sales revenue as well as the development of sales revenue over time. We find the effect of a $\mathrm{NC}^{2}$ sales strategy on a salesperson's sales revenue level to be contingent on his or her experience in gauging customers' purchase likelihood. This effect is consistent with the results of intuition-focused studies in other contexts (Hall et al. 2015). Several environmental factors also influence the sales performance relationship, such as store traffic, which positively influences the relationship between sales level and use of the $\mathrm{NC}^{2}$ sales strategy. Additionally, a salesperson is less likely to benefit from using the $\mathrm{NC}^{2}$ sales strategy if store traffic is low and other salespeople in the store make use of the $\mathrm{NC}^{2}$ sales strategy. Finally, use of the $\mathrm{NC}^{2}$ sales strategy exhibits a positive effect on sales revenue growth if a salesperson espouses a customer relationship-building orientation.

The results of our study provide two essential contributions to current sales and marketing research. First, our study is the first to explore the phenomenon of salespeople's use of customer disengagement strategies. Although research has intensively investigated time allocation across different customers (i.e., customer prioritization) from an organizational perspective (e.g., Homburg, Droll, and Totzek 2008; Saboo et al. 2017), individual salespeople also prioritize decisions at a micro level - that is, customer by customer. Second, our study contributes to existing knowledge by showing under which circumstances salespeople's disengagement strategies may be effective.

Moreover, our findings have actionable implications for practitioners. Salespeople should cut sales interactions short with unpromising prospects to improve their sales performance under three conditions: (1) they have sufficient experience to accurately intuit whether a prospect intends to purchase, (2) sales opportunities are plentiful and uncontested by other salespeople, and (3) they emphasize building relationships with promising prospects.

\section{Conceptual framework}

\section{Definition of the $\mathrm{NC}^{2}$ sales strategy and embedding in sales process}

In what follows, we depict the conceptualization of the $\mathrm{NC}^{2}$ sales strategy in greater detail. We define the $\mathrm{NC}^{2}$ sales strategy as a retail salesperson's behavioral tendency to disengage from an interaction with a customer if he or she judges the customer's purchase likelihood to be low. In other words, the $\mathrm{NC}^{2}$ sales strategy is at its core a straightforward salesperson behavior. This behavior may be regarded as a sales strategy because it comprises salespeople's intentional, planned behavior to achieve a specific outcome, i.e., to save time resources and increase sales performance. Specifically, the $\mathrm{NC}^{2}$ sales strategy represents an adaptive selling strategy (e.g., Alavi et al. 2019). With the $\mathrm{NC}^{2}$ sales strategy, salespeople adapt their selling behavior to customers by disengaging from the customer interaction if they perceive low purchase likelihood. Thus, in the discussion below on the conceptual model and moderator selection, we will draw on adaptive selling theoretical frameworks (e.g., Weitz et al. 1986) and combine theses with research on intuitive decision making (e.g., Gigerenzer and Gaissmaier 2011; Goldstein and Gigerenzer 2002). To provide a deeper characterization of the $\mathrm{NC}^{2}$ sales strategy, we will depict how salespeople embed this disengagement strategy in the sales process. We also will discuss the sales process along the following stages: (1) salespeople's assessment of customer purchase likelihood, (2) salespeople's use of $\mathrm{NC}^{2}$ sales strategy, (3) salespeople's behavior after disengagement from customer interaction.

Marketing and sales research has established that forming impressions of customers constitutes an essential step in salespeople's sales processes (Alavi et al. 2019; McFarland 2019; Weitz 1978). As part of this impression formation, salespeople may assess a customer's purchase likelihood because such information appears highly valuable to salespeople to formulate a fitting sales strategy for the specific customer (Weitz 1978). 
Salespeople's use of the $\mathrm{NC}^{2}$ sales strategy depends on the assessment of the customer's purchase likelihood in the first stage, meaning that after judging that a prospect is unlikely to make a purchase, a salesperson must then decide on an appropriate response. The salesperson must either try harder to uncover a customer need that will result in a purchase or desist attempting to make the sale. If a salesperson adopts the $\mathrm{NC}^{2}$ sales strategy in this situation, he or she tends to decide to disengage from the customer.

After disengaging from a customer interaction due to the $\mathrm{NC}^{2}$ sales strategy, a salesperson will use the time gained. It is important to note that we do not conceptualize salespeople's use of time after implementing the $\mathrm{NC}^{2}$ sales strategy as a constituent part of the strategy itself-conceptually, these are distinct concepts and behaviors. Ideally, using the $\mathrm{NC}^{2}$ sales strategy and thus spending less time with prospects unlikely to be converted will result in more time devoted to prospects with a greater likelihood of conversion. Additionally, the incremental selling time gained via engaging in the $\mathrm{NC}^{2}$ sales strategy process may also be productively used to develop deeper customer relationships with existing customers. For these positive performance behaviors to occur, other prospects must be available and, importantly, the salesperson must be disposed to take advantage of the opportunity to engage with other prospects.

\section{Conceptual model and moderator selection}

The core goal of our paper is to examine the relationship between salespeople's use of the $\mathrm{NC}^{2}$ sales strategy and their sales performance. Our conceptual model on $\mathrm{NC}^{2}$ sales strategy consequences integrates an adaptive selling framework with research on intuitive decision making (e.g., Gigerenzer and Gaissmaier 2011). Both theoretical lenses converge on the idea that performance effects of different decision-making strategies do not automatically exhibit main effects, but that these effects depend on the external environment in which the decision strategy is implemented and individuals' judgment accuracy.

In their seminal work on antecedents and consequences of adaptive selling, Weitz, Sujan, and Sujan (1986, p. 175) emphasize that an adaptive selling strategy will not necessarily exhibit a main effect on sales performance: "Altering sales behaviors (adaptive selling) can be effective or ineffective." Instead, these frameworks underline the fundamentally contingent nature of the adaptive selling strategy: "the relationship between the practice of adaptive selling and selling effectiveness is moderated by the nature of the selling environment and the capabilities of the salespeople" (Weitz et al. 1986, p. 175).

Drawing on both adaptive selling and intuitive decisionmaking research, we likewise expect the effect of the $\mathrm{NC}^{2}$ sales strategy on salespeople's sales performance to depend on moderators related to the immediate selling environment in a store and salespeople's capabilities. Past research on external environment moderators has identified various structural environmental characteristics such as uncertainty, velocity, competitiveness, or opportunities for growth/munificence as being related to selling and marketing effectiveness (Dess and Beard 1984; Davis-Sramek et al. 2010; Feng et al. 2017). Research on adaptive selling strategies (and on firm adaptation strategies) likewise asserts that the environmental opportunities to effectively practice the strategy represent essential external boundary conditions influencing the effectiveness of an adaptive selling strategies (Weitz et al. 1986; Achrol and Etzel 2003). Weitz et al. (1986) proposed that adaptive selling only increases sales effectiveness if salespeople's selling environment comprises a sufficiently large number of customers with varying needs. Intuitively, the benefits of adaptive selling are anticipated to be marginal in an environment where all customers possess similar needs. Research on the effectiveness of intuitive decision making also provides support for the notion of ecological rationality (e.g., Gigerenzer et al. 1999; Gigerenzer 2004; Goldstein and Gigerenzer 2002; Artinger et al. 2015). Ecological rationality refers to the match of the strategy to the structural features of its environment and one's goal in this particular context (Artinger et al. 2015).

In addition to environmental factors, the theoretical framework for adaptive selling emphasizes the importance of salespeople's customer knowledge and needs assessment (Weitz 1978; Szymanski 1988; Ryari et al. 2020). Research on intuitive decision-making strategies builds on this idea through its emphasis on decision maker's judgment accuracy. Research on intuitive decision making has consistently observed a positive relationship between intuitive judgment accuracy and relevant experience (e.g., Gigerenzer and Gaissmaier 2011; Dane and Pratt 2007; Day and Lord 1992; Wally and Baum 1994). Thus, based on the combined insight from adaptive selling and decision-making theoretical frameworks, we expect effects of the $\mathrm{NC}^{2}$ sales strategy on sales performance to depend on moderators related to (1) selling opportunities in salespeople's external environment, and (2) salespeople's accuracy of customer assessments.

Moderators related to salespeople's selling environment We include store traffic and use of the $\mathrm{NC}^{2}$ sales strategy by salesperson's peers as moderators in the conceptual framework of opportunity in salespeople's external selling environment. Both moderators should determine the extent of selling opportunities for an individual salesperson and hence govern effects of the $\mathrm{NC}^{2}$ sales strategy. If store traffic is high and many customers frequent a store, a salesperson's store environment is laden with selling opportunities, conducive to the adoption of the $\mathrm{NC}^{2}$ sales strategy. Conversely, if in a store many salespeople use the $\mathrm{NC}^{2}$ sales strategy, all salespeople are targeting high potential customers, vying for their attention. This intra-store competition may negatively affect selling opportunities for an individual salesperson in such an environment, thus influencing the effectiveness of the $\mathrm{NC}^{2}$ strategy. 
Fig. 1 Conceptual mechanism and moderator selection of the $\mathrm{NC}^{2}$ sales strategy

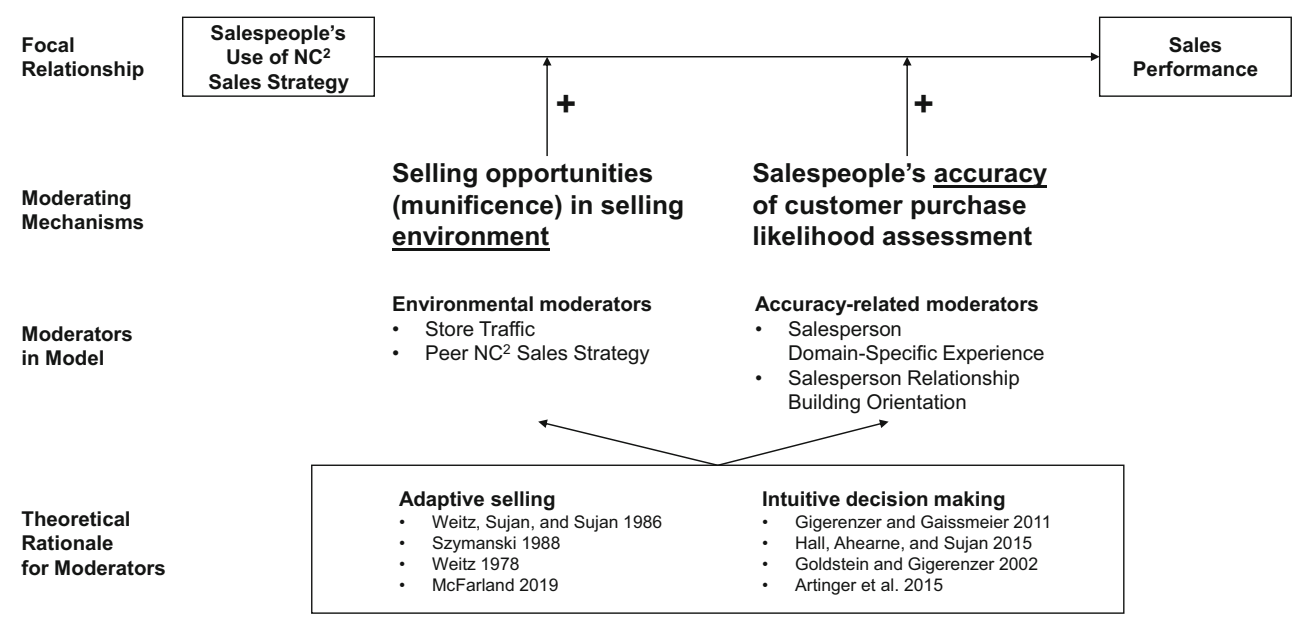

\section{Moderators related to salespeople's judgment accuracy} Initially, we focus on salespeople's domain-specific experience in the moderator category of salespeople's accuracy of judgment. Existing research emphasizes that such experience is indispensable to make accurate assessments of customers, for instance, of their purchase likelihood (Szymanski and Churchill Jr. 1990; Weitz et al. 1986). Moreover, we include salespeople's customer relationship orientation as an additional moderator related to salespeople's accuracy of customer judgment. Relationship orientation reflects salespeople's inclination to build stable relational exchanges with customers (Palmatier et al. 2008). Such salespeople are motivated to invest time and energy in forming bonds with customers which customers value and hence may foster their perceived relationship quality. Relationship quality in turn, due to the enhanced knowledge exchange, has been found to be a key facilitator for salespeople's judgment accuracy (Mullins et al. 2014). Figure 1 illustrates the motivation for the moderator selection and Fig. 2 depicts the conceptual framework for these conditional factors on sales revenue level and sales revenue growth.

\section{Hypotheses}

\section{Environmental factors}

Research on intuitive decision making highlights the importance of the environment in which the intuitive judgments occur (e.g., Artinger et al. 2015; Gigerenzer et al. 1999). The successful use of an intuitive decision-making strategy is determined by its ecological rationality; that is, the match of the strategy to the structural features of its environment and one's goal in this particular context (Artinger et al. 2015). Said another way, ecological rationality refers to determining the environments in which particular decision-making strategies work well and why. Examples of environmental characteristics considered appropriate for intuitive judgments include uncertainty, non-compensatory environments, a need for speedy decisions with incomplete information (Gigerenzer and Gaissmaier 2011). These characteristics would all apply to varying degrees to a typical retail selling environment.

Given this key influence of environmental factors, it is also important to consider opportunities or risks in salespeople's selling environment that may facilitate or impede achieving this

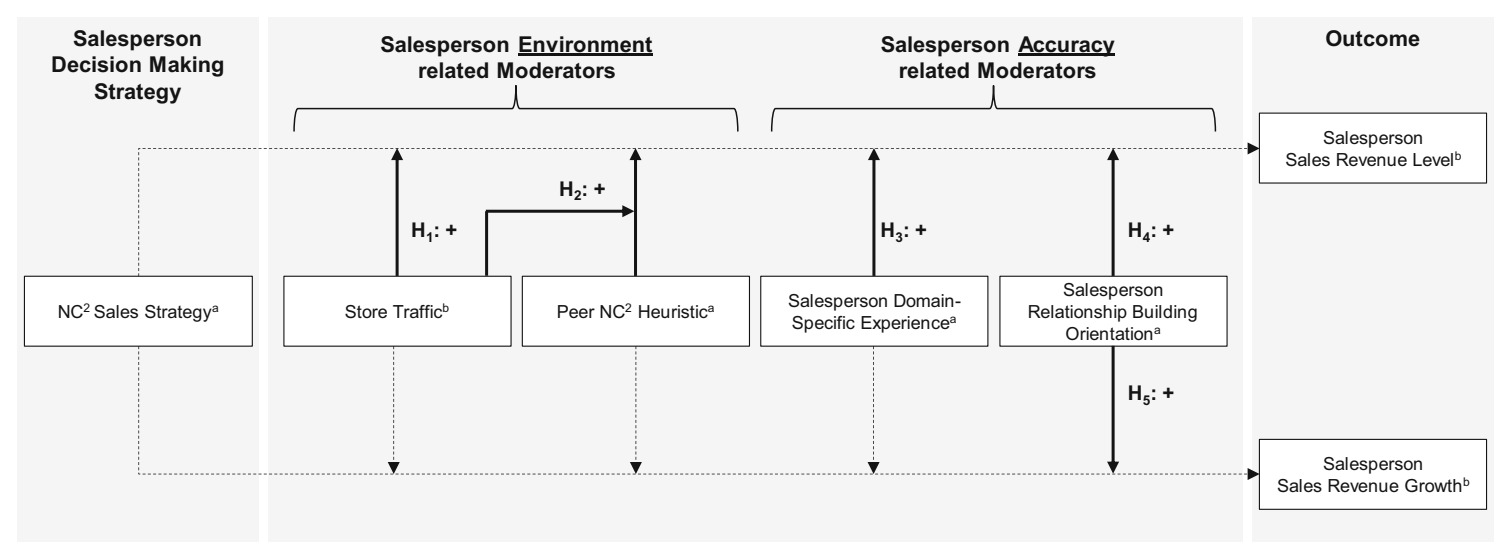

Fig. $2 \mathrm{NC}^{2}$ sales strategy conceptual framework 
goal when using an $\mathrm{NC}^{2}$ sales strategy. For instance, the opportunity to spend freed-up time with prospects is an important environmental condition influencing the $\mathrm{NC}^{2}$ sales strategysales performance relationship. Considerable empirical research examines the impact of traffic (i.e., number of visitors) on store performance and the need to match store labor to traffic in order to increase store performance (e.g., Lam et al. 2001; Perdikaki et al. 2012). As a result, retailers have developed algorithms to drive store location and store traffic and operating procedures to match store labor with traffic and the process of ensuring this match is fundamental to a healthy retail business model. Support for this position was found in a preliminary survey (see Pilot Study in the following section), in which $80 \%$ of the 200 retail salespeople agreed with the statement, "When I end the conversation because of a low purchase likelihood, there are other customers in the store whom I can better serve."

While we argue that an $\mathrm{NC}^{2}$ sales strategy is conducive to sales performance when store traffic is high, we do not anticipate that sales would continuously increase. More specifically, we suggest store traffic to determine salespeople's opportunities to invest time saved through adopting the $\mathrm{NC}^{2}$ sales strategy. If store traffic is high with many prospects in the store, a salesperson can use the time saved from an $\mathrm{NC}^{2}$ sales strategy to close a deal with one of those prospects which will immediately increase his or her sales revenue level, but not his future sales revenue growth. As a result, the potential sales performance benefits of using a sales strategy based on the $\mathrm{NC}^{2}$ sales strategy by salespeople in stores with high traffic should already be included in the sales level of the salesperson. Therefore, we propose the following:

H1: The impact of an $\mathrm{NC}^{2}$ sales strategy on sales revenue is more positive the higher the traffic in a store.

As argued earlier, using an $\mathrm{NC}^{2}$ sales strategy might improve a salesperson's performance if the salesperson is able to invest his or her time on more promising prospects after disengaging from a customer who is unlikely to purchase. The lower the likelihood that more promising prospects are available after disengaging from a customer not intending to make a purchase, the lower the likelihood that the $\mathrm{NC}^{2}$ sales strategy improves a salesperson's performance.

Importantly, the availability of promising prospects may also be influenced by the behavior of a salesperson's colleagues. If other salespeople in a store do not use the $\mathrm{NC}^{2}$ sales strategy, they are more likely to spend time in conversations with customers, which might leave promising customers in the store underserved and available to salespeople using an $\mathrm{NC}^{2}$ sales strategy. An individual salesperson using an $\mathrm{NC}^{2}$ sales strategy will be able to approach more of these underserved prospects and thus increase her own sales performance.

In contrast, if other salespeople in a store intensively use an $\mathrm{NC}^{2}$ sales strategy, every salesperson will spend less time in conversations with prospects of lower purchase likelihood and thus make more approaches to gauge customers' purchase likelihood. As a result, an individual salesperson using the $\mathrm{NC}^{2}$ sales strategy might find fewer opportunities to serve promising customers after disengaging from an unpromising prospect. In such a situation, an $\mathrm{NC}^{2}$ sales strategy might be less instrumental in increasing an individual salesperson's sales performance.

The previous elaboration points to an important contingency in our argumentation: the availability of other customers. Specifically, when store traffic is high, other prospects will be available to be approached after engaging an $\mathrm{NC}^{2}$ sales strategy, even if other salespeople in the store also use an $\mathrm{NC}^{2}$ sales strategy. That is, seeing such a high munificence in the selling environment, we expect that engaging in an $\mathrm{NC}^{2}$ sales strategy in such a situation still exhibits positive effects on sales revenue, despite peer salespeople likewise applying this strategy. In contrast, when store traffic is low, salespeople might compete for the engagement with other customers. In this situation, if other salespeople in the store intensively use an $\mathrm{NC}^{2}$ sales strategy, the likelihood for a focal salesperson being able to spend freed-up time with more promising prospects decreases. Thus, we hypothesize:

H2: If store traffic is low, the impact of an $\mathrm{NC}^{2}$ sales strategy on sales revenue is less positive the more intensively peer salespeople in a store use an $\mathrm{NC}^{2}$ sales strategy.

\section{Salespeople's accuracy of judgment moderators}

What does accuracy mean with respect to using the $\mathrm{NC}^{2}$ sales strategy? When a salesperson judges a prospect unlikely to make a purchase and the customer, in fact, came to the store not intending to make a purchase, then the judgment is accurate. In this case, disengaging from further conversation with a salesperson may be appreciated by the customer as it is an appropriate means by which to meet the customer's needs. To continue to try to sell a customer who does not intend to make a purchase may be interpreted by a customer as exerting sales pressure. Research has consistently found that customers do not like to be pressured by a salesperson to make a purchase when they are not ready (Kirmani and Campbell 2004; Zboja et al. 2016; Alavi et al. 2018). But what if a salesperson's judgement regarding a customer's purchasing likelihood is inaccurate, which means a salesperson concludes that a purchase is unlikely when a customer is actually interested in making a purchase at that time? ${ }^{1}$ In this case, a salesperson has clearly lost a chance to make a sale. Additionally, the customer is likely to feel under-served and may avoid this salesperson and, perhaps, even the store in the future.

\footnotetext{
${ }^{1}$ A salesperson may also err in thinking a customer will make a purchase, when they do not intend to do so. This error is not considered further; however, note that the $\mathrm{NC}^{2}$ strategy is not considered applicable in this situation.
} 
Recent research on intuitive judgments has focused on identifying the personal and situational factors in which intuitive judgments are likely to be accurate (Dane et al. 2012; Kahneman and Klein 2009). This perspective guides our hypothesizing of the performance outcomes associated with the use of the $\mathrm{NC}^{2}$ sales strategy. Specifically, we do not claim that making an intuitive purchasing-likelihood judgment and acting on the $\mathrm{NC}^{2}$ sales strategy will automatically lead to higher or lower performance. Rather, the relationship between use of an $\mathrm{NC}^{2}$ sales strategy and sales performance is likely to depend on conditional factors related to the accuracy of the intuitive judgment leading to the use of the $\mathrm{NC}^{2}$ sales strategy.

The most consistently observed precondition for successfully using intuitive judgments is that the decision maker has expertise to exercise informed (vs. naive) intuition (e.g., Kahneman and Klein 2009; Simon 1992; Weick 1995). Expertise is gained through what is referred to as domain-specific experience. Research suggests that experts, i.e., those with domain-specific experience, can make highly accurate intuitive decisions (Klein 2003). It is argued that this is due the schemas of experts, which have been found to be (1) highly complex and (2) domain relevant (Dane and Pratt 2007). With experience in a particular situation, people begin to recognize patterns or "pattern matching", both consciously and unconsciously, and formulate responses that are contextually appropriate based on recognizing these patterns.

Past sales research underlined that salespeople's experience constitutes a key determinant of sales performance (Churchill Jr et al. 1985; Crosby et al. 1990; Szymanski and Churchill Jr. 1990). Because past sales research has verified this relationship, we do not derive a formal hypothesis on the experienceperformance linkage but concentrate on the interactive effect of salesperson's experience and the $\mathrm{NC}^{2}$ sales strategy. Research in the sales force domain also supports the importance of experience in sales as related to judgment accuracy. According to Hall et al. (2015), salespeople with professional experience are more likely to accurately assess customers' conversion propensity as a result of their greater declarative customer knowledge (Szymanski 1988). According to Weitz et al. (1986), salespeople with more professional experience are able to organize their experiences with customers into categories helpful in future selling situations.

We likewise expect the interactive effect of an $\mathrm{NC}^{2}$ sales strategy and domain-specific experience to affect sales performance level. If a salesperson exhibits a high domain-specific experience, i.e., ability to accurately classify customers, the salesperson will spend less time in customer interactions that do not result in a purchase and relatively more time in customer interactions that result in a purchase. As a result, we anticipate that experience will be positively related to the sales level of the salesperson. Thus:
H3: The impact of an $\mathrm{NC}^{2}$ sales strategy on sales revenue is more positive the greater a salesperson's domain-specific experience.

Another personal characteristic that may enhance performance outcomes when using the $\mathrm{NC}^{2}$ sales strategy is the customer relationship building orientation of the salesperson. Customer relationship building orientation refers to a willingness and desire to work with clients over an extended period to reap future desired sales outcomes (e.g., Schultz and Good 2000). Investing in long-lasting customer relationships has been shown to be related to financial performance (De Wulf et al. 2001) by increasing relationship trust and exchange efficiencies (Palmatier et al. 2008).

Why might a customer relationship building orientation enhance sales outcomes from using an $\mathrm{NC}^{2}$ sales strategy? The basis for this expectation is that a greater customer orientation is expected to increase the accuracy of a salesperson intuition of a customer's purchase intentions during an encounter. One reason for expecting this link is that previous studies of retail salespeople have found that a greater customer focus is associated with greater accuracy in salespeople's customer intuitions judgments (Hall et al. 2015; Homburg et al. 2009; Mullins et al. 2014). Secondly, it has been argued that relationship marketing is not effective for all customers (Cao and Gruca 2005; Reinartz and Kumar 2000). The effectiveness of a customer relationship orientation, for instance, has been found to be dependent on a customer's desire for a relationship with a seller for a specific transaction (Palmatier et al. 2008). If a salesperson's intuitive judgment as to a customer's purchase intentions are accurate as a result of a greater customer relationship orientation, and this is a critical assumption, then disengaging from a customer in this situation is consistent with the needs and desires of the customer in this exchange situation. As a result, we hypothesize:

H4: The impact of an $\mathrm{NC}^{2}$ sales strategy on sales revenue is more positive the greater a salesperson's customer building relationship orientation.

\section{Sales growth}

Beyond the immediate interactive effect of an $\mathrm{NC}^{2}$ sales strategy and relationship building orientation on salespeople's sales revenue level, we propose that time to engage in relationship-building behavior will have an impact on sales growth (Schmitz et al. 2020). Customer relationship building has been shown to lead to more cross-purchasing opportunities (e.g., Page et al. 1996; Reichheld and Sasser Jr. 1990), future store visits, and repurchasing by customers (e.g., Lacey et al. 2007). As a result, it is anticipated that sales growth will occur over an extended period of time due to the evolving nature of customer purchasing behavior as a result of stronger relationships. Again, intensive use of an $\mathrm{NC}^{2}$ sales strategy 
frees up time for salespeople with an orientation towards establishing strong customer relationships to establish such relationships with customers who also have a relationship orientation (Palmatier et al. 2008). This relationship building will have positive performance outcomes over an extended period of time. This is similar to the influence of customer orientation, a closely related concept, on sales growth performance of retail salespeople (Kadic-Magliajlic et al. 2017; Jaramillo and Grisaffe 2009). Therefore, we expect that acting on the $\mathrm{NC}^{2}$ sales strategy will lead to continued sales performance growth when a salesperson is oriented to establishing long-term customer relationships rather than focusing on short-term outcomes. Thus:

H5: The impact of an $\mathrm{NC}^{2}$ sales strategy on sales revenue growth is more positive the greater a salesperson's customer building relationship orientation.

\section{Pilot study}

Prior to examining the advisability of using an $\mathrm{NC}^{2}$ sales strategy guided selling strategy, we conducted a pilot study with two key goals: (1) we sought to acquire an understanding how and to what extent the $\mathrm{NC}^{2}$ sales strategy is currently used by salespeople and (2) to develop and verify a measurement of the $\mathrm{NC}^{2}$ sales strategy. To these ends, we conducted a survey of 200 retail salespeople whom we recruited through the panel provider Prolific. Respondents worked in a variety of retail settings, including fashion (17\%), general merchandise (15\%), electronics (8\%), health and personal care (6\%), furniture (6\%), sporting goods (4\%), and motor vehicles (2\%). The salespeople had an average age of 37.36 years, on average 7.70 years of sales experience, and $64 \%$ were female.

\section{Current state of the $\mathrm{NC}^{2}$ sales strategy in retail's salespeople's practice}

In the pilot study we asked retail salespeople whether they (1) regularly judge the purchasing propensity of customers, and (2) disengage from customers they judge to be not intending to make a purchase at that time. To the question, "Across sales consultations, how frequently do you gauge the likelihood of the customer making a purchase?", $60 \%$ of the retail salespeople in the survey indicated that they "often" or "always" gauge the customer's purchasing likelihood. Only $1 \%$ indicated that they "never" do so. An ANOVA analysis of the responses across types of retailers indicated no significant differences in their responses. So, making a judgment as to the purchasing likelihood of a customer, a necessary first step to using the $\mathrm{NC}^{2}$ sales strategy, appears to be commonly practiced in a variety of retail selling environments.
Survey respondents were asked, "When you consider the purchasing likelihood of a prospective customer to be very low, how often do you proactively-end the conversation with the customer?" Twenty-three percent of the salespeople indicated that they either often or always proactively disengage in this situation and another 33\% indicated that they sometimes disengage. Almost half of the salespeople, $44 \%$, indicated that they either rarely or never proactively disengaged from the customer. It appears that proactively disengaging when a customer is judged to be unlikely to make a purchase is a regular practice for some retail salespeople, but the majority of salespeople avoid proactively disengaging from a potential customer, even when they feel the person is unlikely to make a purchase. As a result, investigating the advisability of embracing the $\mathrm{NC}^{2}$ sales strategy appears to be both relevant and somewhat controversial in a retail selling environment.

\section{Development of $\mathrm{NC}^{2}$ sales strategy measurement}

As $\mathrm{NC}^{2}$ sales strategy is a new concept in the literature, no existing scale was available, so a new scale was developed. We used the pilot study to validate the measurement. Prior to the pilot study, to inform the measurement development, we conducted discussions with retail salespeople and management. One concern expressed was that when judging a customer unlikely to make a purchase, a salesperson had to make a choice between trying harder to make the sale or disengaging from the customer. These alternatives adaptations were considered as one decision, not a sequential decision. So, to reflect how the decision was actually made a measure of this adaptation would need to simultaneously include both alternatives, rather than as separate sequential decisions.

Additionally, discussions with management indicated that they felt that simply dichotomizing the alternative sales approaches, i.e., engage versus disengage with a customer, did not capture differences in how intensively an adaptive sales approach was pursued, as they felt there would be significant differences between salespeople. Management felt that few salespeople would abruptly disengage from a customer out of fear that the customer would react negatively to such behavior. They felt that some salespeople, however, would likely put less effort into making the sale after having arrived at a no-sale judgment and would look for opportunities to gracefully disengage. Alternatively, management had also observed salespeople who were energized and took it as a challenge when a customer communicated hesitation to make a purchase. Again, salespeople varied in the degree to which they felt challenged and needed to demonstrate their selling ability. Accordingly, we concluded that the scale should incorporate both types of sales adaptations along with the opportunity to express the intensity to which each alternative was likely to be adopted. 
For this reason, following established recommendations in organizational methods research (McCloy et al. 2005; Jackson et al. 2000), and after careful deliberation with the company's management as well as within the research team, we decided to measure the $\mathrm{NC}^{2}$ sales strategy as a differential scale. After having concluded that a customer is unlikely to make a purchase, the left-hand anchor entails a salesperson strenuously engaging more deeply with the customer in order to convert them, whereas the right-hand anchor entails a salesperson abruptly disengaging from the customer (in order to serve more promising prospects). Responses on the right-hand side of the mid-point of the scale point to a salesperson increasingly aggressively using the $\mathrm{NC}^{2}$ sales strategy, whereas responses on the left-hand side would point to a salesperson not using the $\mathrm{NC}^{2}$ sales strategy and more aggressively attempting to make a sale.

We followed the scale development procedure proposed by Churchill (1979). We initially generated a pool of seven items and discussed them with practitioners and academics. Based on the discussions, we narrowed the pool of items down to a parsimonious three-item measure of the $\mathrm{NC}^{2}$ sales strategy. The items completed the introductory statement, "When at the beginning of a sales conversation I have the impression that the customer is not likely to purchase, ..." as follows: (1) "... I extend the sales conversation" (anchored as -3) vs. "... I shorten the sales conversation" (anchored as 3); (2) "... I invest more time and effort in the sales conversation" (anchored as -3) vs. "... I invest less time and effort in the sales conversation" (anchored as 3); and (3) “... I make a strong effort to convince the customer" (anchored as -3) vs. "... I scarcely make any effort to convince the customer" (anchored as 3). Three academic experts evaluated the items (Clark and Watson 1995) based on each item's face validity and comprehensibility (on seven-point Likert-type scales; 1 = "not valid at all/not comprehensible at all," 7 = "very valid/very comprehensible"). The experts indicated that the items exhibit face validity and are comprehensible.

To test the scales' psychometric properties, we collected the $\mathrm{NC}^{2}$ sales strategy in the survey of this pilot study. Specifically, to assess reliability and convergent validity, we inspected Cronbach's alpha $(\alpha)$ and conducted confirmatory factor analysis (Diamantopoulos and Winklhofer 2001). Cronbach's alpha value was .775 and thus exceeded the recommended cutoff value of .7 (Nunnally 1978). The results of the factor analysis indicate an average variance extracted (AVE) of .547, which exceeds the recommended threshold value of .5 (Bagozzi and Yi 1988; Fornell and Larcker 1981).

After averaging the three items, $47 \%$ respondents in our preliminary survey had a mean value of above 0 (indicating a tendency to use the $\mathrm{NC}^{2}$ sales strategy) whereas $53 \%$ had a mean value of 0 or lower (indicating a tendency not to use the $\mathrm{NC}^{2}$ sales strategy). We then created two spline variables (Kumar et al. 1995; Johnston 1984), one comprising values from 0 to 3 and one comprising values from -3 to 0 . Thus, the former variable captures a salesperson's tendency to disengage from unpromising prospects and is our measure of the $\mathrm{NC}^{2}$ sales strategy. The latter variable multiplied by -1 captures the opposite strategy, that is, a salesperson's tendency to exhibit persistence and attempting to convince the customer when initially judging a prospect as exhibit a low purchase likelihood. We hereafter label this the $\mathrm{CC}^{2}$ sales strategy ("Continue conversation, convert customer").

Creating spline variables in this way resulted in a measure of the $\mathrm{NC}^{2}$ sales strategy with a mean value of .353 and a standard deviation of .619 , and a measure of the $\mathrm{CC}^{2}$ sales strategy with a mean value of .517 and a standard deviation of .789. To test these transformed variables' convergent and discriminant validity, we collected two additional items in our preliminary survey: (1) the frequency of disengaging from customers with low purchase likelihood, measured on the five-point Likert-type item, "When you consider the purchase likelihood of a prospective customer to be very low, how often do you proactively end the conversation with the customer?" This item positively correlates with our measure of the $\mathrm{NC}^{2}$ sales strategy $(\mathrm{r}=.224, p=.001)$ and marginally negative with our measure of the $\mathrm{CC}^{2}$ sales strategy $(\mathrm{r}=-.135, p=.057) ;(2)$ the frequency of more deeply engaging with customers with low purchase likelihood, measured on the item "When you consider the purchase likelihood of a prospective customer to be very low, how often do keep consulting the customer?". This item negatively correlates with our measure of the $\mathrm{NC}^{2}$ sales strategy $(\mathrm{r}=-.197, p=.005)$ and positively with our measure of the $\mathrm{CC}^{2}$ sales strategy $(\mathrm{r}=.178, p=.012)$. Thus, our measure exhibits convergent and discriminant validity, raising our confidence in our operationalization.

\section{Main study}

To examine the consequences of salespeople's use of the $\mathrm{NC}^{2}$ sales strategy, we sought a context in which customer-salesperson interactions are common, the sales force represents a key communication channel, customers may visit a retail store to gather information about what they would like to buy, and salespeople need to allocate their time across different customers. We selected the fashion and accessories retailing industry as meeting these criteria. Prior research has also examined customer-salesperson interactions in this retailing industry (e.g., Kadic-Magliajlic et al. 2017; Sujan et al. 1986).

The retail organization in the sample is a European company that distributes its products through its own retail outlets. The portfolio comprises different clothing categories (e.g., pants, shirts, shoes) and accessories. The organization has a relatively flat sales force structure with each store led by a sales manager and typically three to six salespeople. Salespeople sell all 
products and do not have a specialized product focus. Full-time salespeople are paid on salary with the opportunity to earn a bonus of $10 \%$ of their salary based on meeting their individual monthly sales target and a 5\% commission on sales above target. Because sales targets and incentives reside on the individual rather than the team level, salespeople might compete with their peers for customers. In addition to selling, store salespeople perform merchandising, inventory, window display, check-out, and store-layout activities. Furthermore, management consciously places an emphasis on salespeople establishing relationships with individual customers.

We collected data from four sources. First, we obtained HR data on all 164 salespeople currently employed in 42 stores by the company, including salespeople's personnel numbers, names, store affiliations, and job titles (store managers, sales advisors, or so-called "mini-jobbers" who are marginally employed only on non-permanent contracts). Second, to collect the use of the $\mathrm{NC}^{2}$ sales strategy as well as further variables, we sent via the company's in-house mail system a paper and pencil survey to all 164 salespeople currently employed by the company. No incentives for participation were offered. Because we repeatedly communicated the survey to salespeople, we managed to receive 135 responses for a response rate of $82.3 \%$. The average age of the salespeople was 30.6 years $(\mathrm{SD}=8.2)$ and $76.1 \%$ were women.

Second, after the fiscal year in which we conducted the survey had ended, we collected salespeople's quarterly sales revenue data from the company's cash management system. We matched this data with the HR data using salespeople's personnel number as the unique identifier. Third, the company monitors traffic in all of its stores via cameras at the entrance. The variable was only available for the previous fiscal year, but management assured to us that the store traffic across different stores is relatively stable because it is largely driven by the attractiveness of a store's location. The variable is such assumed to be an adequate proxy of store traffic in the focal year. We matched store traffic (i.e., the total number of visitors) to our dataset using the store number as the unique identifier.

After matching data from all sources and excluding quarterly observations with missing values, 324 quarterly observations nested in 81 salespeople nested in 29 stores were usable for our analysis. The fact that not all salespeople and stores were used in our analysis is due to two reasons: (1) 50 salespeople were dropped because there was not a full year of sales data based on when they had joined the company. The remaining 85 salespeople were employed in 29 stores. (2) Four further salespeople were dropped because of missing values on our measures. This resulted in our final balanced panel of 81 salespeople in 29 stores, for 324 quarterly observations.

To test for a non-response bias we compared respondents and non-respondents on five sets of variable: (1) average quarterly sales revenues $(\mathrm{t}=-1.7809, p=.077)$; (2) store traffic $(\mathrm{t}=.393, p=.695)$; (3) salespeople's gender, which we coded from salespeople's names $\left(\chi^{2}=.207, p=.649\right)$; (4) salespeople's ethnicity (local vs. foreign), which we coded from salespeople's names $\left(\chi^{2}=.158, p=.691\right)$; and (4) salespeople's position as a store manager $\left(\chi^{2}=.022\right.$, $p=.883)$, sales advisor $\left(\chi^{2}=.855, p=.355\right)$, or minijobber $\left(\chi^{2}=.624, p=.430\right)$. None of the factors considered between respondents and non-respondents are significant, so along with the exceptionally high response rate of $82 \%$ we have a high degree of confidence that non-response bias did not unduly influence our results.

\section{Measurements}

Sales performance Our dependent variable is salespeople's sales revenue generated per quarter over the period of a year (e.g., Bagozzi 1978; Jackson et al. 1983; Weitz 1978). As discussed previously, the data was extracted from the company's cash management system. We log-transformed the variable to mitigate skewness.

$\mathrm{NC}^{2}$ sales strategy The $\mathrm{NC}^{2}$ sales strategy is intended to measure the sales strategy a salesperson is most likely to adopt when they have concluded that a customer is not likely to make a purchase. Said another way, having concluded that a customer is unlikely to make a purchase, does a salesperson tend to wind things down and disengage from the customer or do they take this as a signal that they should more aggressively attempt to make the sale? We used the three items of the semantic differential depicted and developed in the pilot study (sample item: "When at the beginning of a sales conversation I have the impression that the customer is not likely to purchase, ... I invest more time and effort in the sales conversation" (anchored as -3 ) vs. "... I invest less time and effort in the sales conversation" (anchored as 3); please also refer to the Appendix). We then created two spline variables as described previously, one comprising values from 0 to 3 ( $\mathrm{NC}^{2}$ sales strategy) and one comprising values from -3 to 0 , multiplied by $-1\left(\mathrm{CC}^{2}\right.$ strategy). We controlled for this latter variable in our models.

Moderators Domain-specific experience was measured in the salesperson survey using three items that capture salespeople's ability to make accurate judgments about customers' purchase likelihood. This measure was inspired by prior sales force intuition research (Hall et al. 2015; Homburg et al. 2009).

Store traffic was operationalized objectively as the annual number of visitors to a store, divided by 10,000 . There were significant differences across stores due to store locations $(\mathrm{M}=6.240, \mathrm{SD}=2.800, \min =2.182, \max =14.456)$. The final descriptive statistics of this variable matched into the long form of our dataset are provided in Table 1 . 
Peer $\mathrm{NC}^{2}$ sales strategy was calculated as the mean $\mathrm{NC}^{2}$ sales strategy value per store, excluding each focal salesperson. Thus, the variable comprises the mean $\mathrm{NC}^{2}$ sales strategy of each salesperson's colleagues, which is a unique value per salesperson $(\mathrm{M}=.273, \mathrm{SD}=.380)$. For $54 \%$ of respondents, peer $\mathrm{NC}^{2}$ sales strategy had a value of greater than 0 and thus indicated that a salesperson operated in a store where other salespeople exhibited a tendency to disengage from customers with a low purchase probability based on the $\mathrm{NC}^{2}$ sales strategy. Matching the variable into the long form of our dataset results in the descriptive statistics provided in Table 1.176 of the 324 quarterly observations used in our analysis (54\%) had a peer $\mathrm{NC}^{2}$ sales strategy value of greater than 0 .

Relationship building orientation was measured using three items based on a scale by Homburg et al. (2011b). A sample item is "In sales conversations, I often try to establish a personal relationship with my customers." The scale achieved adequate psychometric properties $(\alpha=.746, \mathrm{AVE}=.574)$. Across salespeople, the scale has a high value $(\mathrm{M}=6.428, \mathrm{SD}=.853, \min =2, \max =$ 7 ), which is frequently the case with self-reported survey measures related to desirable behavioral orientations (e.g., Homburg et al. 2011a, 2011b). Again, matching the variable into the long form of our dataset results in the descriptive statistics provided in Table 1. All the interaction variables were mean-centered prior to the estimation.

Controls We controlled for several potential covariates of a salesperson's sales revenue. First, because as outlined previously, salespeople hold different positions that may affect their performance, we controlled for each salesperson's position using two dummy variables extracted from HR records (sales advisor position, mini-job position). The reference group for these dummy variables are salespeople who are store managers. Store managers in our sample have additional administrative responsibilities, but still serve and sell to customers themselves. Second, because salespeople who work longer hours are likely to have higher sales performance, we controlled for whether employees work part-time or full-time using a dummy variable defined from a self-report survey measure. Third, we controlled for adaptive selling, which prior research has shown to be a key determinant of sales performance (Franke and Park 2006; Spiro and Weitz 1990), using four items $(\alpha=.746)$. Fourth, salespeople who apply the $\mathrm{NC}^{2}$ sales strategy might potentially also exhibit higher selling orientation (Saxe and Weitz 1982). To avoid that effects of our $\mathrm{NC}^{2}$ sales strategy variable merely result from its shared variance with selling orientation, we controlled for selling orientation using

Table 1 Descriptive statistics and correlations

\begin{tabular}{|c|c|c|c|c|c|c|c|c|c|c|c|c|c|c|c|}
\hline Variable & V1 & $\mathrm{V} 2$ & V3 & V4 & V5 & V6 & V7 & V8 & V9 & V10 & V11 & V12 & V13 & V14 & V15 \\
\hline \multicolumn{16}{|l|}{$\begin{array}{l}\text { V1: Sales revenue } \\
\text { (log-- } \\
\text { transformed) }\end{array}$} \\
\hline $\begin{array}{l}\mathrm{V} 2: \mathrm{NC}^{2} \text { sales } \\
\text { strategy }\end{array}$ & $-.112^{*}$ & & & & & & & & & & & & & & \\
\hline $\begin{array}{l}\text { V3: } \mathrm{CC}^{2} \text { sales } \\
\text { strategy }\end{array}$ & -.006 & $-.529 * *$ & & & & & & & & & & & & & \\
\hline V4: Store traffic & .033 & -.026 & .076 & & & & & & & & & & & & \\
\hline $\begin{array}{l}\text { V5: Peer } \mathrm{NC}^{2} \text { sales } \\
\text { strategy }\end{array}$ & $-.116^{*}$ & -.031 & $.154 * *$ & $-.116^{*}$ & & & & & & & & & & & \\
\hline $\begin{array}{l}\text { V6: } \\
\text { Domain-specific } \\
\text { experience }\end{array}$ & $-.138^{*}$ & .016 & $.158 * *$ & -.025 & -.061 & & & & & & & & & & \\
\hline $\begin{array}{l}\text { V7: Relationship } \\
\text { building } \\
\text { orientation }\end{array}$ & $.177^{* *}$ & -.042 & $.245^{* *}$ & -.079 & .050 & .008 & & & & & & & & & \\
\hline V8: Time & .046 & -.000 & .000 & .000 & -.000 & -.000 & -.000 & & & & & & & & \\
\hline $\begin{array}{l}\text { V9: Sales advisor } \\
\text { position }\end{array}$ & .065 & $-.346^{* *}$ & $.266^{* * *}$ & .068 & $.127^{*}$ & -.020 & .105 & .000 & & & & & & & \\
\hline $\begin{array}{l}\text { V10: Mini-job posi- } \\
\text { tion }\end{array}$ & $-.644 * *$ & $.250 * *$ & $-.124 *$ & -.043 & -.003 & .078 & $-.224 * *$ & -.000 & $-.362 * *$ & & & & & & \\
\hline $\begin{array}{l}\text { V11: Part-time posi- } \\
\text { tion }\end{array}$ & $-.279 * *$ & $-.117 *$ & $.150 * *$ & -.029 & .073 & .071 & -.029 & -.000 & $.493 * *$ & .054 & & & & & \\
\hline $\begin{array}{l}\text { V12: Adaptive } \\
\text { selling }\end{array}$ & -.062 & .065 & $.255^{* *}$ & -.073 & $.111^{*}$ & $.251^{* *}$ & $.454 * *$ & .000 & -.090 & $.118^{*}$ & .073 & & & & \\
\hline $\begin{array}{l}\text { V13: Selling } \\
\text { orientation }\end{array}$ & -.057 & -.051 & .087 & .068 & -.082 & .108 & $.215^{* *}$ & .000 & -.024 & .043 & -.092 & .008 & & & \\
\hline $\begin{array}{l}\text { V14: Competitive } \\
\text { intensity }\end{array}$ & -.088 & $-.184 * *$ & $.142 *$ & .042 & .042 & .082 & $.317 * *$ & .000 & $-.150^{* *}$ & .032 & $-.126^{*}$ & $.160 * *$ & $.337 * *$ & & \\
\hline V15: Gender & -.038 & $-.225 * *$ & $.139 *$ & -.101 & .017 & $-.185^{* *}$ & $-.121 *$ & .000 & $.297 * *$ & -.037 & $.368 * *$ & -.080 & $-.195 * *$ & $-.151 * *$ & \\
\hline $\mathrm{M}$ & 10.185 & .300 & 1.218 & 6.227 & .273 & 4.556 & 6.428 & 2.500 & $\mathrm{~L}^{\mathrm{a}}$ & $\mathrm{a}^{\mathrm{a}}$ & ${ }^{\mathrm{a}}$ & 6.206 & 2.465 & 5.156 & ${ }^{\mathrm{a}}$ \\
\hline SD & .698 & .685 & 1.012 & 2.555 & .378 & 1.382 & .850 & 1.120 & $-^{\mathrm{a}}$ & $\underline{-}^{\mathrm{a}}$ & $-^{\mathrm{a}}$ & .766 & 1.128 & 1.228 & $\underline{-}^{\mathrm{a}}$ \\
\hline
\end{tabular}

$* p<.05, * * p<.01$ (two-tailed). ${ }^{\text {a }}$ Dummy variable 
five items $(\alpha=.758)$. Fifth, because a salesperson's revenue may depend on competition, we controlled for competitive intensity (Jaworski and Kohli 1993) using three items $(\alpha=.839)$. Sixth and last, to account for potential demographic influences, we controlled for a salesperson's gender as coded from HR data. All survey scales are provided in the Appendix, and Table 1 lists the descriptive statistics and correlations. Discriminant validity was indicated by the squared correlations between the latent constructs being smaller than the AVE from each construct (Fornell and Larcker 1981).

\section{Analytical approach}

We took a growth analysis approach, which is regularly applied in psychological and organizational research (e.g., Bindl et al. 2012; Chan and Schmitt 2000), to represent repeated measures of the dependent variable. Growth analysis is recommended in marketing research for examining longitudinal data at the individual level (Palmatier et al. 2013; Steenkamp and Baumgartner 2000). Thus, we specified the following regression equation for salesperson $\mathrm{i}$ in quarter $\mathrm{t}$ :

Sales revenueit $=$

b1 $* \mathrm{NC} 2$ sales strategyi $+\mathrm{b} 2 * \mathrm{CC} 2$ sales strategyi $+\mathrm{b} 3 *$ store trafficit +

b4 4 peer NC2 sales strategyi + b5 ${ }^{*}$ domain-specific experiencei +

$\mathrm{b} 6 *$ relationship building orientationi $+\mathrm{b} 7 *$ timet +

$\mathrm{b} 8 * \mathrm{NC} 2$ sales strategyi $*$ store traffici+

b9*NC2 sales strategyi*peer NC2 sales strategyi+

b10*peer NC2 sales strategyi*store trafficit +

b11*NC2 sales strategyi*peer NC2 sales strategyi*store trafficjt+

b12*NC2 sales strategyi*domain-specific experiencei+

b13*NC2 sales strategyi*relationship building orientationi+

b14*NC2 sales strategyi*timet +

b15*relationship building orientationi*timet+

b16*NC2 sales strategyi*relationship building orientationi*timet+

$$
\text { bn*controln }+ \text { b0 }+ \text { eit }
$$

In this equation, time assumes a value of 1 in the first quarter, 2 in the second quarter, 3 in the third quarter, and 4 in the fourth and final quarter of our data. Its coefficient $\left(b_{7}\right)$ thus provides the linear growth trend of sales revenue over our study period. Coefficients that pertain to the multiplication of time with a third variable show how this third variable affects growth of sales revenue. To illustrate, $b_{14}$ denotes how an increase in how aggressively the $\mathrm{NC}^{2}$ sales strategy is generally used affects the linear growth trend of a salesperson's sales revenue. Because we mean-centered all interacting variables, the main effect of each variable provides the effect on the mean level of sales revenue in the study period.

Note that our data is hierarchical, with quarters nested in salespeople nested in stores. To take this hierarchical structure into account, we estimated a three-level mixed effects model, also taking account for the fact that store traffic resides on the store level and thus interactions with store level are cross-level interactions. We analyzed the model in two steps. First, we examined a model which includes main effects only. Second, we added the interactive effects to the model.

\section{Results}

We report the results in Table 2 and provide the interaction plots in Figs. 3 and 4. Interpretation of the results are based on Model 2, which is the full model including all main, interactive, and controlled effects. We first note that neither the $\mathrm{NC}^{2}$ sales strategy $\left(\mathrm{b}_{2}=1.743, p>.05\right)$ nor the $\mathrm{CC}^{2}$ sales strategy (b3 $=-.076, p>.05$ ) exhibit a main effect on sales revenue, which suggests that salespeople who intensively use these sales strategies are not per se more or less successful than salespeople who do not.

$\mathrm{H} 1$ predicted that when store traffic was high, then using an $\mathrm{NC}^{2}$ sales strategy would be related to high sales performance. This was hypothesized because when store traffic was high, other sales opportunities were more likely to be available to the salesperson. The results provide support for this hypothesis as the interactive effect of the $\mathrm{NC}^{2}$ sales strategy and store traffic on sales revenue was positive and statistically significant $\left(\mathrm{b}_{8}=.983, p<.05\right)$.

$\mathrm{H} 2$ hypothesized that if store traffic is low, ending a sales encounter quickly based on the $\mathrm{NC}^{2}$ sales strategy would be related to lower sales revenue for salespeople whose peers use the $\mathrm{NC}^{2}$ sales strategy as well. To test this proposition, we first inspect the two-way interactive effect between $\mathrm{NC}^{2}$ sales strategy and peer $\mathrm{NC}^{2}$ sales strategy, which is positive and significant $\left(\mathrm{b}_{9}=1.932, p<.05\right)$. To test whether this interaction is affected by store traffic as suggested in $\mathrm{H}_{2}$, we inspect the three-way interactive effect between $\mathrm{NC}^{2}$ sales strategy, peer $\mathrm{NC}^{2}$ sales strategy, and store traffic. The interactive effect is significantly positive $\left(b_{11}=3.481, p<.05\right)$. Thus, if store traffic decreases, the interactive effect between $\mathrm{NC}^{2}$ sales strategy and peer $\mathrm{NC}^{2}$ 
Table 2 Results

DV: Sales revenue (log-transformed)

\begin{tabular}{|c|c|c|c|}
\hline & \\
\hline & $\begin{array}{l}\text { Model } 1 \\
\text { Main effects }\end{array}$ & $\begin{array}{l}\text { Model } 2 \\
\text { Full model }\end{array}$ & $\begin{array}{l}\text { Model } 3 \\
\text { Robustness model }\end{array}$ \\
\hline \multicolumn{4}{|l|}{ Main effects } \\
\hline $\mathrm{NC}^{2}$ sales strategy & -0.057 & 1.743 & 0.645 \\
\hline $\mathrm{CC}^{2}$ sales strategy & -0.035 & -0.076 & -0.058 \\
\hline Store traffic & 0.003 & 0.574 & 0.629 \\
\hline Peer $\mathrm{NC}^{2}$ sales strategy & -0.176 & 1.020 & 1.176 \\
\hline Domain-specific experience & -0.035 & -0.054 & -0.035 \\
\hline Relationship building orientation & 0.062 & 0.006 & 0.015 \\
\hline Time & 0.029 & 0.066 & 0.066 \\
\hline \multicolumn{4}{|l|}{ Interactive effects } \\
\hline $\mathrm{NC}^{2}$ strategy $\times$ store traffic $(\mathrm{H} 1:+)$ & - & $0.983 *$ & $1.075 * * *$ \\
\hline $\mathrm{NC}^{2}$ strategy $\times$ peer $\mathrm{NC}^{2}$ sales strategy & - & $1.932 *$ & $2.207 * *$ \\
\hline Peer $\mathrm{NC}^{2}$ sales strategy $\times$ store traffic & - & $1.008 *$ & $1.116^{* *}$ \\
\hline $\mathrm{NC}^{2}$ strategy $\times$ peer $\mathrm{NC}^{2}$ sales strategy $\times$ store traffic $(\mathrm{H} 2:+)$ & - & $3.481 *$ & $3.841^{* *}$ \\
\hline $\mathrm{NC}^{2}$ strategy $\times$ domain-specific experience $(\mathrm{H} 3:+)$ & - & $0.157 * * *$ & $0.194 * *$ \\
\hline $\mathrm{NC}^{2}$ strategy $\times$ relationship building orientation $(\mathrm{H} 4:+)$ & - & -0.142 & -0.161 \\
\hline $\mathrm{NC}^{2}$ strategy $\times$ time & - & -0.029 & -0.029 \\
\hline Relationship building orientation $\times$ time & - & $0.047 *$ & 0.047 \\
\hline $\mathrm{NC}^{2}$ strategy $\times$ relationship building orientation $\times$ time $(\mathrm{H} 5:+)$ & - & $0.172 * * *$ & $0.172 *$ \\
\hline \multicolumn{4}{|l|}{ Controls } \\
\hline Sales advisor position & -0.111 & -0.092 & $-0.082^{*}$ \\
\hline Mini-job position & $-1.566 * * *$ & $-1.528 * * *$ & $-1.493 * * *$ \\
\hline Part-time position & $-0.326 * *$ & $-0.321 * * *$ & $-0.327 * * *$ \\
\hline Adaptive selling & 0.049 & 0.058 & 0.040 \\
\hline Selling orientation & -0.015 & -0.027 & -0.024 \\
\hline Competitive intensity & -0.069 & -0.047 & $-0.054 * *$ \\
\hline Gender & 0.027 & 0.041 & 0.046 \\
\hline \multicolumn{4}{|l|}{ Control for endogeneity of the $\mathrm{NC}^{2}$ sales strategy } \\
\hline Gaussian copula control function term & - & - & 0.371 \\
\hline Number of observations & 324 & 324 & 324 \\
\hline
\end{tabular}

$* p<.05, * * p<.01, * * * p<.001$ (two-tailed); unstandardized coefficients

sales strategy becomes more negative. This provides support for $\mathrm{H} 2$.

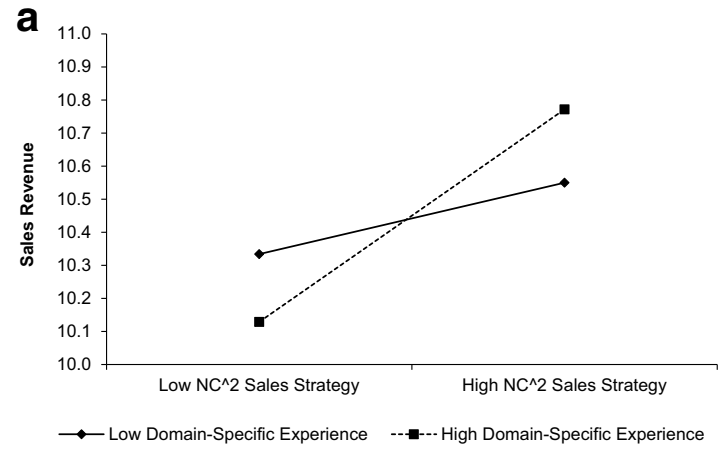

Fig. 3 Two-way interaction diagrams
$\mathrm{H} 3$ proposed that salespeople with greater domain-specific experience who use the $\mathrm{NC}^{2}$ sales strategy would have higher sales performance. Confirming this hypothesis, we found a

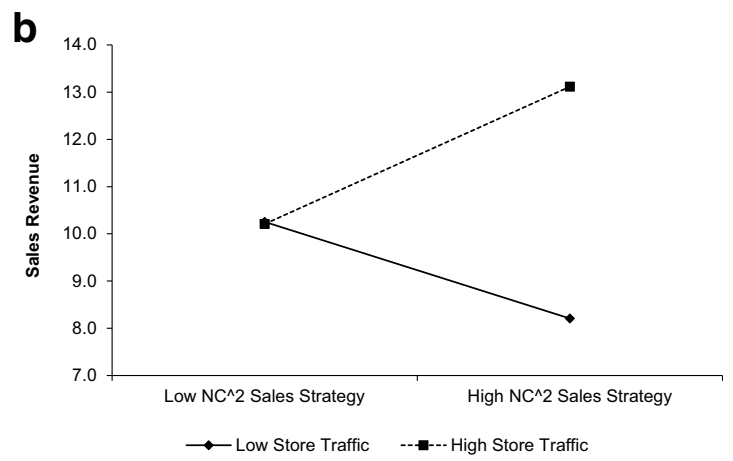


Fig. 4 Three-way interaction diagrams
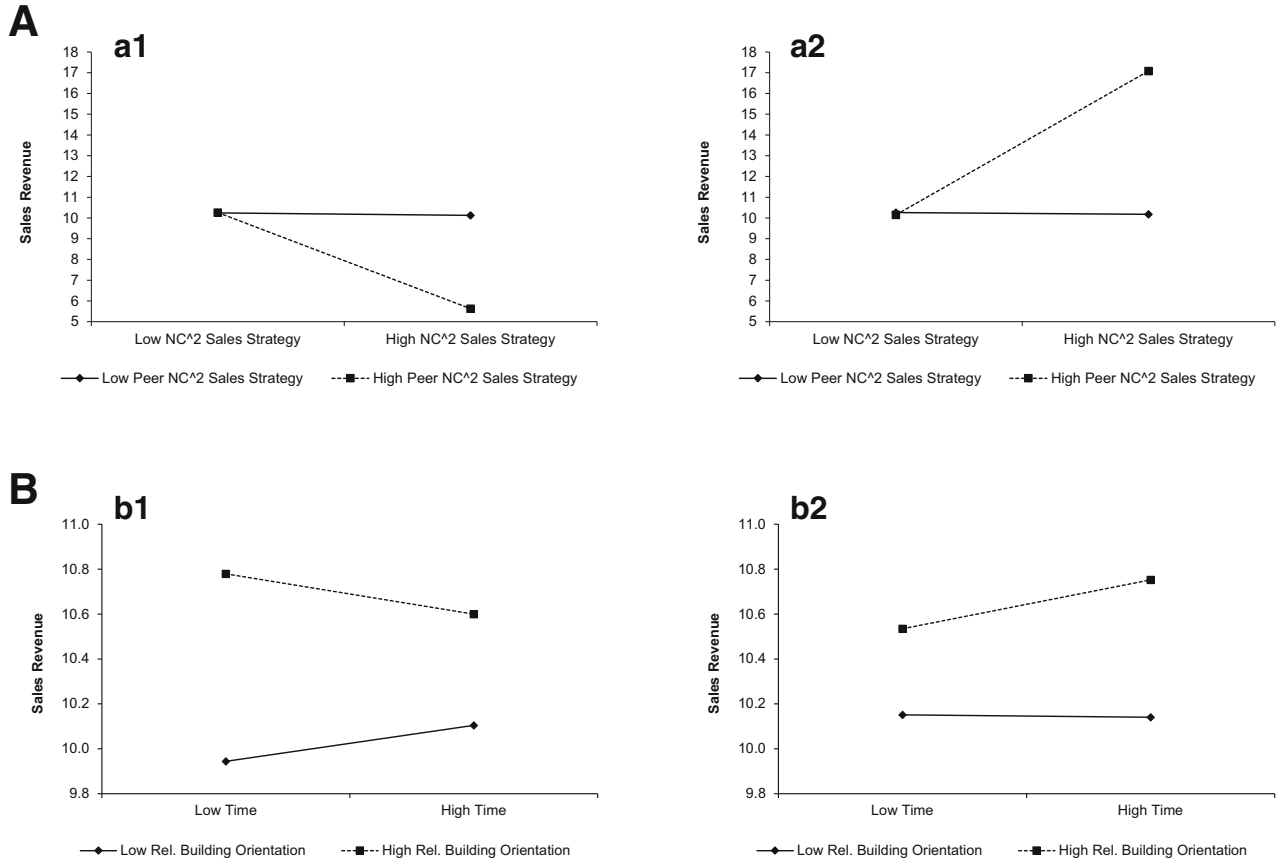

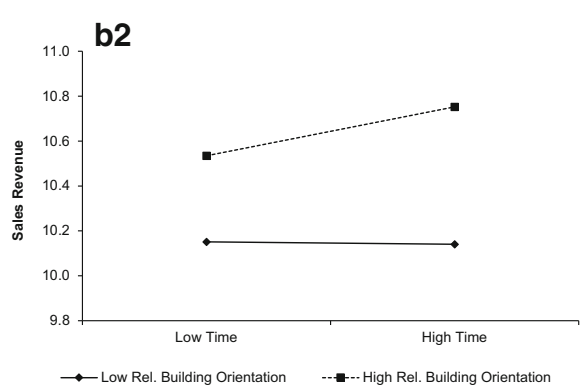

positive interactive effect of quickly ending sales engagements when a customer is judged as unlikely to purchase and domain-specific experience on sales revenue $\left(b_{12}=.157\right.$, $p<.001)$.

$\mathrm{H} 4$ hypothesized that aggressive use of the $\mathrm{NC}^{2}$ sales strategy would increase sales revenue level to a greater extent for salespeople with high customer relationship building orientation. The results of the model estimation do not provide support for $\mathrm{H} 4$, as indicated by a non-significant interaction effect of the $\mathrm{NC}^{2}$ sales strategy and salespeople's relationship building orientation $\left(\mathrm{b}_{13}=-.142, p>.05\right)$.

$\mathrm{H} 5$ hypothesized that ending a sales encounter quickly based on the $\mathrm{NC}^{2}$ sales strategy would be related to greater sales revenue growth for salespeople who are oriented toward customer relationship building. The results of the model estimation provide support for $\mathrm{H} 5$, as indicated by a significant, positive interaction effect of the $\mathrm{NC}^{2}$ sales strategy, salespeople's relationship building orientation and time on the sales revenue $\left(\mathrm{b}_{16}=.172, p<.001\right)$.

\section{Robustness checks and supplemental analyses}

Endogeneity Our measure of $\mathrm{NC}^{2}$ sales strategy may be endogenous if salespeople decide to use the $\mathrm{NC}^{2}$ sales strategy on the basis of their sales performance level. We therefore examined the correlation between $\mathrm{NC}^{2}$ sales strategy and sales revenue in the quarter before the salesperson survey. This correlation is insignificant $(\mathrm{r}=-.140, p=.211)$, counter to the contention that a salesperson's use of the $\mathrm{NC}^{2}$ sales strategy is biased by salespeople's recent performance. To further test for potential endogeneity, we used a Gaussian copula control function approach (Park and Gupta 2012). This approach corrects for endogeneity in a regressor without using instruments by controlling for the inverse normal of the cumulative density functions of the regressor. As required by this approach, our measurement of the $\mathrm{NC}^{2}$ sales strategy is not normally distributed (Shapiro-Wilk test: $\mathrm{W}=.821$, $p<.001$ ). Model 3 in Table 2 comprises a replication of our model while controlling for a Gaussian copula control function term and bootstrapping the standard errors based on 1000 iterations. Results fully replicate our previous results, suggesting that endogeneity of the $\mathrm{NC}^{2}$ sales strategy variable did not unduly influence our findings.

Store-level effects Our results point to interesting store-level effects beyond the individual salesperson. Specifically, an individual salesperson is more likely to benefit from using the $\mathrm{NC}^{2}$ sales strategy when store traffic is high. When store traffic is low, they are less likely to benefit from using the $\mathrm{NC}^{2}$ sales strategy - particularly if other salespeople in the store use the $\mathrm{NC}^{2}$ sales strategy as well. However, our previous results have not been able to answer the question how the $\mathrm{NC}^{2}$ sales strategy affects overall store performance. Specifically, given the risks inherent in the $\mathrm{NC}^{2}$ sales strategy, is there a deleterious impact on overall store sales revenue if the entire staff uses the $\mathrm{NC}^{2}$ sales strategy? To answer this question, we collapsed our dataset on store level, which resulted in 116 quarterly observations of store sales revenue clustered in 29 stores. We then estimated the effect of salespeople's mean level of $\mathrm{NC}^{2}$ sales strategy on salespeople's aggregate sales revenue. We did not find any significant effects of the mean level of the $\mathrm{NC}^{2}$ sales strategy on either store sales revenue level $\left(\mathrm{b}_{\mathrm{NC}}{ }^{2}\right.$ strategy $\left.=-.007, p=.975\right)$ or growth $\left(\mathrm{b}_{\mathrm{NC}}^{2}\right.$ Strategy $\times$ time $\left.=.004, p=.875\right)$. Thus, while an individual 
salesperson may experience benefits or disbenefits from aggressively using the $\mathrm{NC}^{2}$ sales strategy, in our dataset, on the store level, these effects seem to offset each other. We discuss this finding in greater detail below.

\section{General discussion}

The overall objective of this study was to determine if disengaging from customers judged to be unlikely to make a purchase, referred to as the $\mathrm{NC}^{2}$ sales strategy, is on balance a good or poor adaptive sales strategy. A preliminary study confirmed that most retail salespeople surveyed regularly judge their customer's likelihood to make a purchase early in the sales encounter. Moreover, both the preliminary survey and this study, however, indicate that a sales strategy of disengaging from a sales interaction with a customer judged to be unlikely to make a purchase is not one used by most retail salespeople. This practice receives some support here as there is no direct influence of using the $\mathrm{NC}^{2}$ sales strategy and sales performance.

On the other hand, the benefits of working harder to make the sale when a customer appears to be unlikely to make a sale may be over-sold. The results of this study indicate that in certain circumstances disengaging from a customer judged not likely to make a purchase may be positively associated with salesperson sales performance. As has been found in other situations, positive outcomes from intuitive judgments is associated with domain specific experience. In this case, use of the $\mathrm{NC}^{2}$ sales strategy by salespeople with greater experience in making accurate judgments is positively associated with higher performance. Second, higher performance was found among salespeople who use the $\mathrm{NC}^{2}$ sales strategy in stores with high traffic. Third, if store traffic is low, colleagues' use of the $\mathrm{NC}^{2}$ sales strategy reduces the effectiveness of an individual salesperson's use of the $\mathrm{NC}^{2}$ sales strategy. Finally, salespeople with more of a customer relationship orientation who use the $\mathrm{NC}^{2}$ sales strategy are found to increase their rate of sales growth over the year. It is important to keep in mind, however, that the positive outcomes found in this study do not apply to using an extreme or abrupt form of disengagement, as none of the salespeople in this study indicated they engaged in this type of selling behavior.

\section{Theory development}

Our study contributes to the literature on personal selling as we examine a new salesperson sales strategy that may exhibit beneficial or harmful effects on salespeople's sales performance depending on contingencies related to salespeople's judgment accuracy and selling environment. Specifically, our findings add knowledge to research on adaptive selling strategies. While the rich literature field of adaptive selling substantially advanced knowledge on consequences of adaptive selling strategies under different salesperson contingencies (e.g., Alavi et al. 2019), to date, marketing and sales research has not analyzed a specific adaptive selling strategy based on salespeople's assessment of customers' purchase likelihood.

Moreover, this study adds to a growing focus on the use of intuition in sales (Homburg et al. 2009; Mullins et al. 2014; Hall et al. 2015). We shed light on what appears to be a widely used intuitive judgment as to the likelihood of the interaction resulting in a sale. The performance outcomes in this study are in line with those of recent research on the use of intuitive judgments, which focuses on identifying when the use of intuitive judgments is effective. As was found in earlier studies of sales intuition judgments, domain specific experience and a customer relationship orientation is associated with positive performance outcomes. The list of conditional characteristics associated with improved outcome performance is extended in this study to include store traffic. It is not enough to disengage from unpromising prospects, opportunities must be present to use the available time to engage with other customers.

This study provides additional evidence of the positive relationship between effective use of intuitive judgments and sales performance outcomes. Prior sales force research has found when used in proper circumstances and by qualified individuals, intuitive judgments are associated with favorable outcomes in individual customer transactions (Hall et al. 2015) and account profitability (Mullins et al. 2014). These performance outcomes are extended in this study to show that when used by experienced salespeople under the right circumstance the use of intuitive judgments can produce positive sales performance for the salesperson. Additionally, evidence is provided that when combined with a customer relationship orientation, use of the $\mathrm{NC}^{2}$ sales strategy may result in greater sales growth on an ongoing basis, at least in the short term.

Many micro- or transactional level issues remain to be explored, however. A focus on the accuracy of salespeople's customer purchasing propensity intuitions is warranted. At what point in the interaction or even pre-interaction does this intuitive judgment take place? Is the initial intuitive judgement revised during the interaction, referred to as deliberative judgment (Hall et al. 2015)? Does the timing and sequence of judgments differ between more and less successful salespeople? On what basis do salespeople make these judgments and are some dimensions better predictors of customer intentions than others?

Information from the pilot survey in this study may help inform these questions. When asked what factors they used to gauge the likelihood of a prospective customer making a purchase, $83 \%$ of the salespeople said they either often or always based their judgment on what a customer says and the questions they ask. Other factors mentioned, however, included 
customer body language (60\% often/always considered), customer communication style (55.5\%), and customer decisiveness $(51.5 \%)$. Only $12.5 \%$ indicated that they often or always considered the customer's appearance when making this judgement.

Given the possible positive outcomes associated with accurate purchasing propensity judgments and use of the $\mathrm{NC}^{2}$ sales strategy, increasing the accuracy of these intuitive judgments could be key. When and how do salespeople learn from their mistakes in making this judgment? Can salespeople be trained to accelerate their ability to accurately judge customer purchasing propensity, or does it require trial and error? That training may be challenging is suggested by research finding that individuals who lack adequate domain knowledge, for instance, have inflated selfassessments of their own ability to make accurate judgments (Kruger and Dunning 1999). Research on object classification errors, on the other hand, has established that robust learning can enhance how accurately people are able to classify members of a schema category (Vigo et al. 2015). This research suggests that learning to make correct classification decisions can take place through exposure to practice sessions and even suggests training strategies for enhancing classification performance (Ziegler and Vigo 2018). Accordingly, there is basis for optimism regarding positive outcomes from training on classifying the purchasing intentions of customers. Malcom Gladwell (2007) arrives at this same conclusion when exploring thin-slicing in his popular book, Blink.

How important is the process of disengagement in driving sales performance? Research has shown, for instance, that people's knowledge and behavior towards others is influenced by behavior schemas about the likely interpersonal consequences of behaviors towards another person (Kammrath 2011; Habel et al. 2017). What antecedents impact adopting an $\mathrm{NC}^{2}$ sales strategy-based sales approach and/or execution of the disengagement process? Are there other, more productive sales strategies available when a customer is judged to be unlikely to make a purchase?

An additional research approach would be to focus on the consequences of an inaccurate intuitive judgment of a customer's purchasing propensity in the future. If inaccurate, is there a "lost forever" consequence for the salesperson and/or store or is there a "win-back" opportunity? How much of an opportunity is there to obtain a sale when the customer comes to the store with the intention of just looking and not buying? Are there intuitive heuristics and/or sales strategies that can be judiciously employed to encourage a purchase in this situation? How likely is a customer to not intend to make a purchase in one department, but then make a purchase in another department of the store? Addressing questions of this nature are probably best approached from a customer's perspective as opposed to the salesperson focus this study has adopted.

There are also macro-level questions to be addressed as well. While $\mathrm{NC}^{2}$ may be related to individual salesperson performance, we did not find a positive effect on store-level performance when individual salespeople use the $\mathrm{NC}^{2}$ sales strategy. Our analysis was constrained by a relatively low number of stores $(N=29)$. Future research on store-level effects might examine store-level effects and contingencies more closely. For example, cross-fertilization of making accurate intuitive judgments and enacting effective $\mathrm{NC}^{2}$-based sales behavior may lead to greater overall store sales performance. At the same time, might the use of $\mathrm{NC}^{2}$ be detrimental to the sales performance of other salespeople in the store or to the teamwork and culture of the store? Is it possible that an over-emphasis on selling may be detrimental to the other nonselling tasks, which may be important to the overall performance of the store? What is the impact of the sales compensation system on the use of $\mathrm{NC}^{2}$ ? Would the results of this study hold in different retail settings where the customer instore behaviors and information needs differ from those for fashion retailers? Even more broadly, how does the process of intuitive judgment and disengagement behavior work in a $\mathrm{B} 2 \mathrm{~B}$ setting? Would use of the $\mathrm{NC}^{2}$ sales strategy be associated with positive sales outcomes when deeper customer relationships are the norm and salespeople initiate the customer conversation as is typical in many B2B settings?

\section{Managerial implications}

First, significant sales growth may be associated with using an NC2 sales strategy, if the retail salesperson possesses a highlevel experience and thus can accurately gauge customers' purchase likelihood. We find that if salespeople with high domain-specific experience disengage based on a $\mathrm{NC}^{2}$ sales strategy, their (logged) sales performance may increase by $6 \%$ (see Fig. 3). Even for salespeople with little domain-specific experience, engaging in the $\mathrm{NC}^{2}$ sales strategy may slightly increase sales performance by $2 \%$.

Second, taking advantage of an opportunity-rich sales environment is important. Accordingly, store traffic is a resource that is found to be related to sales performance. High store traffic and acting aggressively based on the $\mathrm{NC}^{2}$ sales strategy can increase salespeople's sales performance by $28 \%$. A similarly aggressive disengagement behavior by a salesperson in a store with low traffic is associated with $20 \%$ lower sales performance.

Third, if store traffic is low and a salesperson's peers aggressively use the $\mathrm{NC}^{2}$ sales strategy as well, a salesperson is less likely to benefit from using the $\mathrm{NC}^{2}$ sales strategy. Specifically, using the $\mathrm{NC}^{2}$ sales strategy in this situation leads to a sales performance decrease of $45 \%$. Conversely, if store traffic is low and a salesperson's peers 
do not use the $\mathrm{NC}^{2}$ sales strategy, using the $\mathrm{NC}^{2}$ sales strategy increases the salesperson's sales performance by $1 \%$. Interestingly, when store traffic is high, other salespeople's use of the $\mathrm{NC}^{2}$ sales strategy seems to cross-fertilize a focal salesperson's use of the $\mathrm{NC}^{2}$ sales strategy and leads to an increase of sales performance by $68 \%$. A potential explanation for this finding is that if store traffic is high, the more salespeople use the $\mathrm{NC}^{2}$ sales strategy, the more they collectively "separate the wheat from the chaff," increasing a focal salesperson's likelihood that his or her next customer interaction will be a successful one.

Fourth, salespeople should use time savings gained through the $\mathrm{NC}^{2}$ sales strategy to build relationships with promising prospects. Forging relationships with such prospects increases salespeople's performance growth. Rapid disengagement from customers judged to be unpromising combined with relationship building orientation can enhance sales performance by $24 \%$ as time increases. Conversely, with low relationship building orientation quick disengagement may not prove as instrumental and decrease sales performance by $1 \%$.

From a sales manager perspective, the $\mathrm{NC}^{2}$ sales strategy constitutes a delicate tool that salespeople should employ with some caution; while it may increase salespeople's sales performance, it may also exert negative effects on salespeople's performance and customer relationships if misapplied. Consequently, sales managers must coach and monitor salespeople's use of the $\mathrm{NC}^{2}$ sales strategy because its application is challenging. Specifically, sales managers should focus on three issues to enhance the likelihood of salespeople's successful use of the $\mathrm{NC}^{2}$ sales strategy: (1) ensure that salespeople exhibit sufficient expertise in judging customers' purchase intention, (2) verify that salespeople's selling environment does indeed allow time savings, and (3) coach salespeople to employ the time saved through the $\mathrm{NC}^{2}$ sales strategy for relationship building with promising prospects.

\section{Limitations and avenues for future research}

Our study exhibits several limitations that provide fruitful avenues for future research. First, this study evaluates the use of an intuitive judgment that is made in a situation where time for customer interaction is constrained and there is likely to be a purchase decision made in a single sales interaction. As is common in most empirical field studies, factors relevant to the chosen research setting will influence the research. In this case, the range and level of store traffic patterns, may have influenced the results. In other retail settings, this might not be true, instead influencing the effectiveness of disengaging from customers perceived to be less likely to make a purchase. Likewise, management placed an emphasis on salespeople developing relationships with their customers as it was felt that this would lead to greater purchase frequency and cross-selling opportunities. This may not be the case in the other retail settings.

Second, the company permitted us to match sales performance to individual salespeople and to obtain multiple periods of sales performance in order to evaluate both the level of performance and the growth velocity over a period of a year. Had we worked with a different company, the nature of the sales interaction and the purchase decision process may have led to different relationships. For instance, when a customer has an immediate need for a store's product, say a snack food item, then a purchase is almost always the result and there is little need for the salesperson to make an intuitive judgment as to a customer's likelihood of making a purchase. Although the generalizability of our results should be established, gaining the cooperation of an organization in providing access to their salespeople and matching this information to multiple periods of sales is rare and can be daunting.

Third, our study focuses on selected moderators that determine how the $\mathrm{NC}^{2}$ sales strategy affects a salesperson's sales performance. We encourage future studies to examine further contingencies. For example, how does the $\mathrm{NC}^{2}$ sales strategy interact with other sales strategies? With respect to the moderating effect of peers' use of the NC2 sales strategy, what is the role of the accuracy of peers' judgment of customers' purchase likelihood? How do or should selling teams use of the $\mathrm{NC}^{2}$ sales strategy? Answering questions like these could substantially improve our theoretical understanding of the $\mathrm{NC}^{2}$ sales strategy and allow for further important managerial implications.

Fourth, our study focuses on a sales strategy based on judging whether a customer is unlikely to purchase. Similarly, salespeople might alter their sales strategy if they judge that a customer is likely to purchase. Future research might explore whether and how salespeople make these judgements and whether, how, and with what effect they alter their sales strategy in response. Like in our study, the accuracy of salespeople's judgment as well as opportunities in the selling environment might play an important role in this respect.

Fifth, we measured the $\mathrm{NC}^{2}$ sales strategy in a single survey in the fiscal year for which we also extracted our dependent variable of sales revenue. This raises endogeneity concerns because salespeople's choice of the $\mathrm{NC}^{2}$ strategy might potentially depend on their recent performance. While as discussed previously our results seem robust, a more rigorous approach would have been to either measure the $\mathrm{NC}^{2}$ sales strategy repeatedly throughout the focal year, or, alternatively, measure it before the start of the focal year. To maintain causal order, we encourage future studies to more carefully design data collections when combining survey and secondary sales data.

Funding Open Access funding enabled and organized by Projekt DEAL. 


\section{Appendix}

Table 3 Survey measurements

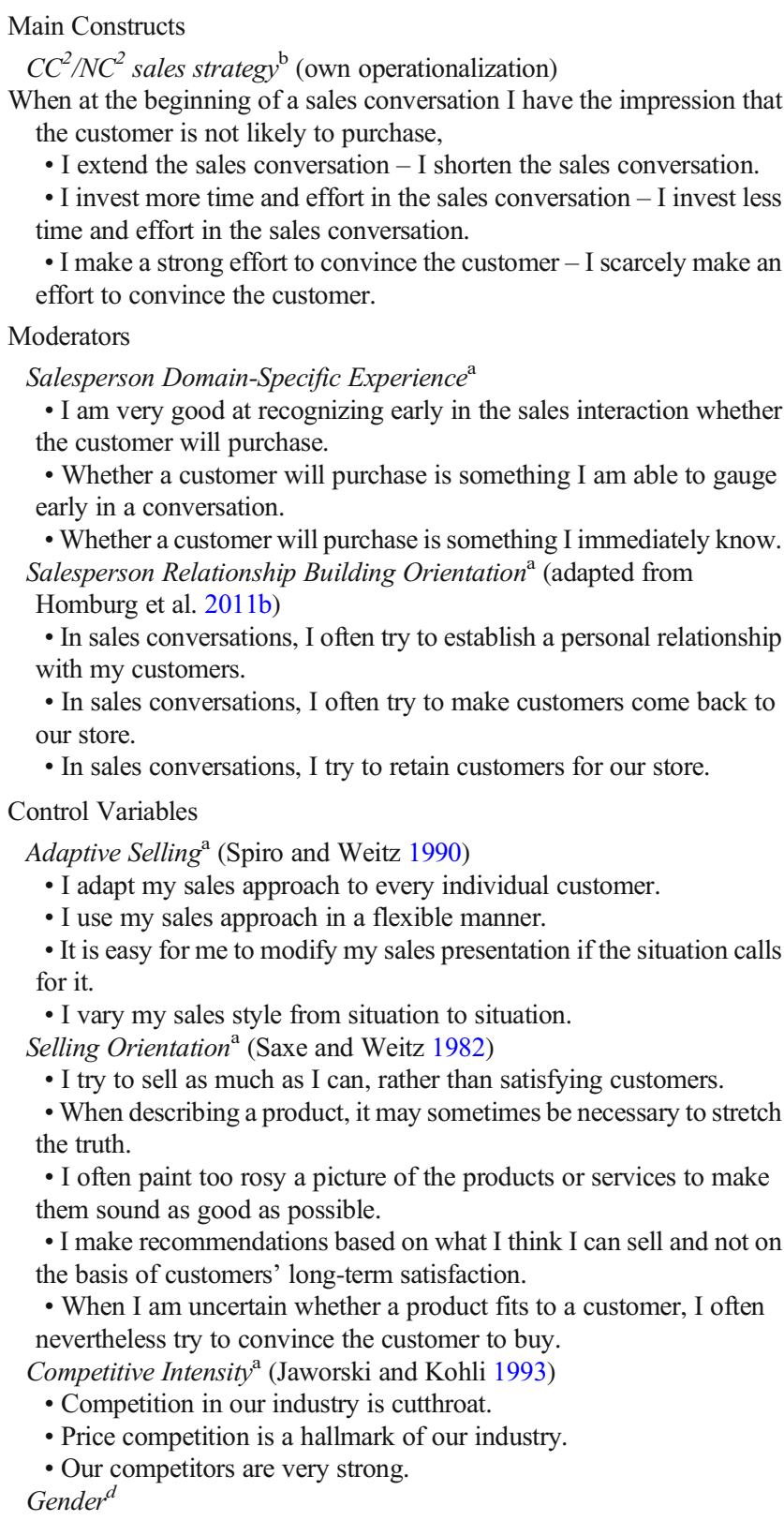

a Seven-point Likert scale (anchored "strongly disagree" and "strongly agree")

${ }^{\mathrm{b}}$ Seven-point differential. Two spline variables were created, one comprising values from 0 to 3 ( $\mathrm{NC}^{2}$ sales strategy) and one comprising values from -3 to 0 , multiplied by -1 ( $\mathrm{CC}^{2}$ strategy)

${ }^{\mathrm{c}}$ Open text field

${ }^{\mathrm{d}}$ Male/Female. Based on first name from personnel records. Country setting is Germany and we did not encounter gender-neutral names
Open Access This article is licensed under a Creative Commons Attribution 4.0 International License, which permits use, sharing, adaptation, distribution and reproduction in any medium or format, as long as you give appropriate credit to the original author(s) and the source, provide a link to the Creative Commons licence, and indicate if changes were made. The images or other third party material in this article are included in the article's Creative Commons licence, unless indicated otherwise in a credit line to the material. If material is not included in the article's Creative Commons licence and your intended use is not permitted by statutory regulation or exceeds the permitted use, you will need to obtain permission directly from the copyright holder. To view a copy of this licence, visit http://creativecommons.org/licenses/by/4.0/.

\section{References}

Achrol, R. S., \& Etzel, M. J. (2003). The structure of reseller goals and performance in marketing channels. Journal of the Academy of Marketing Science, 31(2), 146-163.

Alavi, S., Habel, J., Schmitz, C., Richter, B., \& Wieseke, J. (2018). The risky side of inspirational appeals in personal selling: When do customers infer ulterior salesperson motives? Journal of Personal Selling \& Sales Management, 38(3), 323-343.

Alavi, S., Habel, J., \& Linsenmayer, K. (2019). What does adaptive selling mean to salespeople? An exploratory analysis of practitioners' responses to generic adaptive selling scales. Journal of Personal Selling \& Sales Management, 39(3), 254-263.

Artinger, F., Petersen, M., Gigerenzer, G., \& Weibler, J. (2015). Heuristics as adaptive decision strategies in management. Journal of Organizational Behavior, 36(1), 33-52.

Bagozzi, R. P. (1978). Salesforce performance and satisfaction as a function of individual difference, interpersonal, and situational factors. Journal of Marketing Research, 15(4), 517-531.

Bagozzi, R. P., \& Yi, Y. (1988). On the evaluation of structural equation models. Journal of the Academy of Marketing Science, 16(1), 74 94.

Bindl, U. K., Parker, S. K., Totterdell, P., \& Hagger-Johnson, G. (2012). Fuel of the self-starter: How mood relates to proactive goal regulation. Journal of Applied Psychology, 97(1), 134-150.

Cao, Y., \& Gruca, T. S. (2005). Reducing adverse selection through customer relationship management. Journal of Marketing, 69(4), 219-229.

Chan, D., \& Schmitt, N. (2000). Interindividual differences in intraindividual changes in proactivity during organizational entry: A latent growth modeling approach to understanding newcomer adaptation. Journal of Applied Psychology, 85(2), 190-210.

Churchill, G. A. (1979). A paradigm for developing better measures of marketing constructs. Journal of Marketing Research, 16(1), 64-73.

Churchill Jr., G. A., Hartley, S. W., \& Walker Jr., O. C. (1985). The determinants of salesperson performance: A meta-analysis. Journal of Marketing Research, 22(2), 103-118.

Clark, L. A., \& Watson, D. (1995). Constructing validity: Basic issues in objective scale development. Psychological Assessment, 7(3), 309319.

Crosby, L. A., Evans, K. R., \& Cowles, D. (1990). Relationship quality in service selling: An interpersonal influence perspective. Journal of Marketing, 54(3), 68-81.

CSO Insights. (2011). 2011 sales performance optimization benchmark. Littleton: Miller Heiman Group. 
Dane, E., \& Pratt, M. G. (2007). Exploring intuition and its role in managerial decision making. Academy of Management Review, 32(1), $33-54$.

Dane, E., Rockmann, K. W., \& Pratt, M. G. (2012). When should I trust my gut? Linking domain expertise to intuitive decision-making effectiveness. Organizational Behavior and Human Decision Processes, 119(2), 187-194.

Davis-Sramek, B., Germain, R., \& Iyer, K. (2010). Supply chain technology: The role of environment in predicting performance. Journal of the Academy of Marketing Science, 38(1), 42-55.

Day, D. V., \& Lord, R. G. (1992). Expertise and problem categorization: The role of expert processing in organizational sense-making. Journal of Management Studies, 29, 35-47.

De Wulf, K., Odekerken-Schröder, G., \& Iacobucci, D. (2001). Investments in consumer relationships: A cross-country and crossindustry exploration. Journal of Marketing, 65(4), 33-50.

Dess, G. G., \& Beard, D. W. (1984). Dimensions of organizational task environments. Administrative Science Quarterly, 29(1), 52-73.

Diamantopoulos, A., \& Winklhofer, H. M. (2001). Index construction with formative indicators: An alternative to scale development. Journal of Marketing Research, 38(2), 269-277.

Dimple, K. (2017). Customer relationship management (CRM), customer satisfaction and customer lifetime value (CLV) in retail. Review of Professional Management, 15(2), 55-60.

Feng, H., Morgan, N. A., \& Rego, L. L. (2017). Firm capabilities and growth: The moderating role of market conditions. Journal of the Academy of Marketing Science, 45(1), 76-92.

Fornell, C., \& Larcker, D. F. (1981). Evaluating structural equation models with unobservable variables and measurement error. Journal of Marketing Research, 18(1), 39-50.

Franke, G. R., \& Park, J.-E. (2006). Salesperson adaptive selling behavior and customer orientation: A meta-analysis. Journal of Marketing Research, 43(4), 693-702.

Gensler, S., Neslin, S. A., \& Verhoef, P. C. (2017). The showrooming phenomenon: it's more than just about price. Journal of Interactive Marketing, 38, 29-43.

Gigerenzer, G. (2004). Fast and frugal heuristics: The tools of bounded rationality. In D. J. Koehler \& N. Harvey (Eds.), Blackwell handbook of judgment and decision making (pp. 62-88). Hoboken: Blackwell Publishing.

Gigerenzer, G., \& Gaissmaier, W. (2011). Heuristic decision making. Annual Review of Psychology, 62, 451-482.

Gigerenzer, G., Gaissmaier, W., \& The ABC Research Group. (1999). Simple heuristics that make us smart. New York: Oxford University Press.

Goldstein, D. G., \& Gigerenzer, G. (2002). Models of ecological rationality: The recognition heuristics. Psychological Review, 109(1), 75-90.F.

Graham, J. (2013). Sales strategy: Why closing ratios are so low. American Salesman, 58(2), 16-21.

Grewal, D., \& Levy, M. (2007). Retailing research: Past, present, and future. Journal of Retailing, 83(4), 447-464.

Habel, J., Alavi, S., \& Pick, D. (2017). When serving customers includes correcting them: Understanding the ambivalent effects of enforcing service rules. International Journal of Research in Marketing, 34(4), 919-941.

Hall, Z. R., Ahearne, M., \& Sujan, H. (2015). The importance of starting right: The influence of accurate intuition on performance in salesperson-customer interaction. Journal of Marketing, 79(3), 91109.

Homburg, C., Droll, M. \& Totzek, D. (2008). Customer Prioritization: Does it Pay off, and how Should it be Implemented? Journal of Marketing, 72(5), 110-130.

Homburg, C., Wieseke, J., \& Bornemann, T. (2009). Implementing the marketing concept at the employee-customer interface: The role of customer need knowledge. Journal of Marketing, 73(4), 64-81.
Homburg, C., Muller, M., \& Klarmann, M. (2011a). When should the customer really be king? On the optimum level of salesperson customer orientation in sales encounters. Journal of Marketing, 75(2), $55-74$.

Homburg, C., Muller, M., \& Klarmann, M. (2011b). When does salespeople's customer orientation lead to customer loyalty? The differential effects of relational and functional customer orientation. Journal of the Academy of Marketing Science, 39(6), 795-812.

Jackson, D. W., Keith, J. E., \& Schlacter, J. E. (1983). Evaluation of selling performance: A study of current practices. Journal of Personal Selling \& Sales Management, 3(2), 42-51.

Jackson, D. N., Wroblewski, V. R., \& Ashton, M. C. (2000). The impact of faking on employment tests: Does forced choice offer a solution? Human Performance, 13(4), 371-388.

Jaramillo, F., \& Grisaffe, D. B. (2009). Does customer orientation impact objective sales performance? Insights from a longitudinal model in direct selling. Journal of Personal Selling \& Sales Management, 29(2), 167-178.

Jaworski, B. J., \& Kohli, A. K. (1993). Market orientation: Antecedents and consequences. Journal of Marketing, 57(3), 53-70.

Johnston, J. (1984). Econometric methods (3d ed.). New York: McGrawHill.

Kadic-Magliajlic, S., Micevski, M., Arslanagic-Kalajdzic, M., \& Lee, N. (2017). Customer and selling orientation of retail salespeople and the sales manager's ability-to-perceive-emotions: A multi-level approach. Journal of Business Research, 80, 53-62.

Kahneman, D., \& Klein, G. (2009). Conditions for intuitive expertise: A failure to disagree. American Psychologist, 64(6), 515-526.

Kammrath, L. K. (2011). What we think we do (to each other): How personality can bias behavior schemas through the projection of if-then profiles. Journal of Personality and Social Psychology, 101(4), 754-770.

Kirmani, A., \& Campbell, M. C. (2004). Goal seeker and persuasion sentry: How consumer targets respond to interpersonal marketing persuasion. Journal of Consumer Research, 31(3), 573-582.

Klein, G. A. (2003). Intuition at work: Why developing your gut instincts will make you better at what you do. New York: Currency/ Doubleday.

Koetsier, J. (2018). The new retail: Showrooming, webrooming, and scanswapping are how millennials shop. Retrieved March 26, 2020 from https://www.inc.com/john-koetsier/showroomingwebrooming-scanswapping-are-new-retail.html.

Kruger, J., \& Dunning, D. (1999). Unskilled and unaware of it: How difficulties in recognizing one's own incompetence lead to inflated self-assessments. Journal of Personality and Social Psychology, 77, $1121-1134$.

Kumar, N., Scheer, L., \& Steenkamp, J. (1995). The effects of perceived interdependence on dealer attitudes. Journal of Marketing Research, 32(4), 348-356.

Lacey, R., Suh, J., \& Morgan, R. M. (2007). Differential effect of preferential treatment levels on relational outcomes. Journal of Service Research, 9(3), 241-256.

Lam, S. Y., Vandenbosch, M., Hulland, J., \& Pearce, M. (2001). Evaluating promotions in shopping environments: Decomposing sales response into attraction, conversion, and spending effects. Marketing Science, 20(2), 194-215.

Malcom Gladwell (2007). Blink: The Power of Thinking Without Thinking. Back Bay Books, New York.

McCloy, R. A., Heggestad, E. D., \& Reeve, C. L. (2005). A silk purse from the sow's ear: Retrieving normative information from multidimensional forced-choice items. Organizational Research Methods, $8(2), 222-248$.

McFarland, R. G. (2019). A conceptual framework of macrolevel and microlevel adaptive selling theory, setting a research agenda, and suggested measurement strategies. Journal of Personal Selling \& Sales Management, 39(3), 207-221. 
Mullins, R., Ahearne, M., Lam, S., Hall, Z., \& Boichuk, J. (2014). Know your customer: How salesperson perceptions of customer relationship quality form and influence account profitability. Journal of Marketing, 78(6), 38-58.

Narayandas, D. (2005). Building loyalty in business markets. Harvard Business Review, 83(9), 131-139.

Nunnally, J. C. (1978). Psychometric theory. New York: McGraw-Hill.

Page, M., Pitt, L., \& Berthon, P. (1996). Analysing and reducing customer defections. Long Range Planning, 29(6), 821-834.

Palmatier, R. W., Scheer, L. K., Evans, K. R., \& Arnold, T. J. (2008). Achieving relationship marketing effectiveness in business-tobusiness exchanges. Journal of the Academy of Marketing Science, 36, 174-190.

Palmatier, R. W., Houston, M. B., Dant, R. P., \& Grewal, D. (2013). Relationship velocity: Toward a theory of relationship dynamics. Journal of Marketing, 77(1), 13-30.

Park, S., \& Gupta, S. (2012). Handling endogenous regressors by joint estimation using copulas. Marketing Science, 31(4), 567-586.

Perdikaki, O., Kesavan, S., \& Swaminathan, J. M. (2012). Effect of retail store traffic on conversion rate and sales. Manufacturing and Service Operations Management, 14(1), 145-162.

Rapp, A., Baker, T. L., Bachrach, D. G., Ogilvie, J., \& Beitelspacher, L. S. (2015). Perceived customer showrooming behavior and the effect on retail salesperson self-efficacy and performance. Journal of Retailing, 91(2), 358-369.

Reichheld, F. F., \& Sasser Jr., W. E. (1990). Zero defections: Quality comes to services. Harvard Business Review, 68(5), 105-111.

Reinartz, W. J., \& Kumar, V. (2000). On the profitability of long-life customers in a noncontractual setting: An empirical investigation and implications for marketing. Journal of Marketing, 64(4), 17-35.

Reynolds, K. E., \& Beatty, S. E. (1999). Customer benefits and company consequences of customer-salesperson relationships in retailing. Journal of Retailing, 75(1), 11-32.

Ryari, H., Alavi, S., \& Wieseke, J. (2020). Drown or blossom? The Impact of Perceived Chronic Time Pressure on Retail Salespeople's Performance and Customer-Salesperson Relationships. Journal of Retailing. https://doi.org/10.1016/j.jretai. 2020.05.005.

Saboo, A. R., Kumar, V., \& Anand, A. (2017). Assessing the impact of customer concentration on initial public offering and balance sheetbased outcomes. Journal of Marketing, 81(6), 42-61.

Saxe, R., \& Weitz, B. A. (1982). The SOCO scale: A measure of the customer orientation of salespeople. Journal of Marketing Research, 19(3), 343-351.

Schmitz, C., Friess, M., Alavi, S., \& Habel, J. (2020). Understanding the impact of relationship disruptions. Journal of Marketing, 84(1), 6687.

Schultz, R. J., \& Good, D. J. (2000). Impact of the consideration of future sales consequences and customer-oriented selling on long-term buyer-seller relationships. Journal of Business \& Industrial Marketing, 15(4), 200-215.

Simon, H. A. (1992). What is an explanation of behavior? Psychological Science, 3(3), 150-161.

Spiro, R. L., \& Weitz, B. A. (1990). Adaptive selling: Conceptualization, measurement, and nomological validity. Journal of Marketing Research, 27(1), 61-69.

Steenkamp, J.-B. E. M., \& Baumgartner, H. (2000). On the use of structural equation models for marketing modeling. International Journal of Research in Marketing, 17(2/3), 195-202.

Sujan, M., Bettman, J. R., \& Sujan, H. (1986). Effects of consumer expectations on information processing in selling encounters. Journal of Marketing Research, 23(4), 346-353.

Szymanski, D. M. (1988). Determinants of selling effectiveness: The importance of declarative knowledge to the personal selling concept. Journal of Marketing, 52(1), 64-77.

Szymanski, D. M., \& Churchill Jr., G. A. (1990). Client evaluation cues: A comparison of successful and unsuccessful salespeople. Journal of Marketing Research, 27(2), 163-174.

Verhoef, P. C., Neslin, S. A., \& Vroomen, B. (2007). Multichannel customer management: Understanding the research-shopper phenomenon. International Journal of Research in Marketing, 24(2), 129148.

Vigo, R., Evans, S., \& Owens, J. (2015). Categorization behavior in adults, adolescents, and attention-deficit/hyperactivity disorder adolescents: A comparative investigation. The Quarterly Journal of Experimental Psychology, 68(6), 1058-1072.

Wally, S., \& Baum, J. R. (1994). Personal and structural determinants of the pace of strategic decision making. Academy of Management Journal, 37(4), 932-956.

Weick, K. E. (1995). What theory is not, theorizing is. Administrative Science Quarterly, 40(3), 385-390.

Weitz, B. A. (1978). Relationship between salesperson performance and understanding of customer decision making. Journal of Marketing Research, 15(4), 501-516.

Weitz, B. A., Sujan, H., \& Sujan, M. (1986). Knowledge, motivation, and adaptive behavior: A framework for improving selling effectiveness. Journal of Marketing, 50(4), 174-191.

Zboja, J., Clark, R., \& Haytko, D. (2016). An offer you can't refuse: Consumer perceptions of sales pressure. Journal of the Academy of Marketing Science, 44, 806-821.

Ziegler, D., \& Vigo, R. (2018). Classification errors and response times over multiple distributed sessions as a function of category structure. Memory \& Cognition, 46, 1041-1057.

Publisher's note Springer Nature remains neutral with regard to jurisdictional claims in published maps and institutional affiliations. 